\title{
Swarm intelligence?
}

\section{Stock opinions of the crowd and stock returns*}

\author{
Bastian Breitmayer ${ }^{\dagger}$ Filippo Massari ${ }^{\ddagger}$ Matthias Pelster $\S$
}

\begin{abstract}
We find that crowds' analyses of stocks, disclosed on a social investment platform, provide explanatory power for stock returns. Exploiting a novel dataset that contains more than 14.9 million individual stock assessments for 10,452 stocks over the period from August 1, 2007, to July 15, 2015, our study shows that social networks may add valuable information for explaining future and abnormal stock returns. We find that a portfolio based on social media opinions yields a monthly excess return of $3.3 \%$. We provide a theoretical rationale for our findings based on the argument that the platform is subject to fewer institutional restrictions and is designed more efficiently for prediction than financial markets.
\end{abstract}

Keywords: Crowd intelligence; stock returns; abnormal returns; non-bayesian updating.

JEL Classification: D14, G11, G23.

\footnotetext{
*Financial support by the Fritz Thyssen Stiftung (Grant number 20.16.0.018WW) is gratefully acknowledged. We thank Sharewise for providing access to their database. We thank Sonja Warkulat for outstanding research support. We are grateful for comments from Monika Gehde-Trapp, Julia Kapraun, Tunde Kovacs, Corey Shank, Paul Slovic, Jianshen Wang, Danika Wright, and participants of the Research of Behavioral Finance Conference 2016 in Amsterdam, the 2016 Annual Meeting of the Academy of Behavioral Finance and Economics in Las Vegas, the 4th Paris Financial Management Conference, the Financial Management Association Europe Meeting 2017 in Lisbon, and the Financial Management Association Annual Meeting 2017 in Boston. A previous version of the paper was a semifinalist for the Best Paper Award at the 2017 FMA Annual Meeting. Any errors, misrepresentations, and omissions are our own.

†Queensland University of Technology School of Accountancy. GPO Box 2434, Brisbane QLD 4001, Australia.e-mail: bastian.breitmayer@qut.edu.au.

${ }^{\ddagger}$ University of New South Wales, Sydney, NSW 2052 Australia. Phone: +61 (2) 9385 5754, e-mail: f.massari@unsw.edu.au.

§Paderborn University, Warburger Str. 100, 33098 Paderborn, Germany. Phone: +49 5251602927, e-mail: matthias.pelster@upb.de.
} 


\section{Introduction}

This study investigates the explanatory power of stock price analyses shared on a social network designed to discuss stocks. Understanding the relevance of information shared within such a social network is important for several reasons. First, buy and sell recommendations made in these networks may have implications for returns of individual investors who execute financial transactions accordingly! $!^{1}$ Second, regulators need to adjust their compliance requirements for financial advisers as social media is disrupting the traditional client-adviser relationship and shows an increasing number of users (The Securities and Exchange Commission, 2012). Third, reacting to the new competition, established investment banks such as Goldman Sachs have started to adopt the business model of online social investment networks.2 Thus, studying the explanatory power of information shared on social investment platforms helps to improve our understanding of developments in the financial services industry.

The idea of social investment platforms such as Sharewise, Seeking Alpha, StockTwits, or Estimize is to make use of the wisdom of crowds. This concept, first discussed by Galton (1907), is simple: on aggregate, many users reach better decisions than an individual (professional). Galton (1907) demonstrates that under certain circumstances, social community decisions are more precise than estimates of an individual or a few experts (see also Lorge et al., 1958, Hommes et al., 2005; Yaniv and Milyavsky, 2007). Surowiecki (2004) specifies this phenomenon as the wisdom of crowds and contends that individual estimates contain subjective errors. A piece of identical information may be perceived and evaluated differently depending on personal preferences, expectations and experience (Vasile et al., 2012). By combining all individual estimates, individual errors will disappear while the true information remains.

It is particularly important that the recommendation in the context of social investment

\footnotetext{
${ }^{1}$ Data obtained from SimilarWeb-website traffic statistics indicates that the social network, which we use in this study, i.e., Sharewise, has over 300,000 monthly visitors. Of those visitors, approximately $15 \%$ arrive from financial news websites and approximately $9 \%$ continue to online banking websites, which indicates that the Sharewise community uses the platform in the context of investment decisions.

${ }^{2}$ Goldman Sachs has invested in a social investment platform, i.e., Motif Investing.
} 
platforms such as Sharewise does not comprise the individual peer-based advice but rather the compiled advice of the network, as empirical research provides evidence that individual investors are unable to outperform the market on a long-term basis (see, e.g., Barber and Odean, 2000; Bollen and Busse, 2004, Busse et al., 2010). In fact, neither professional fund managers (Busse et al., 2010) nor private households exhibit performance persistence in their trading activities (Barber and Odean, 2000).

Our paper empirically and theoretically examines whether stock price analyses of a social crowd provide explanatory power for future stock returns. Our empirical investigations are based on crowd stock recommendations obtained from the social investment platform Sharewise (www. sharewise.com). We rely on Sharewise data because the platform offers its users an instant and standardized forum for sharing stock opinions. Investors can observe the results of shared stock price assessments in one final quantified target price associated with a simple buy or sell recommendation and, thus, do not face the risk of misinterpreting verbalized opinions (e.g., expressed in textual form as a comment). The platform provider (Sharewise) aggregates all individual user opinions and reports a crowd consensus target price with a corresponding buy or sell recommendation as soon as new information - in the form of a new stock assessment by one of its users - becomes available. We exploit all 14.9 million stock price opinions that were disclosed on the website between August 2007 and July 2015, covering 10,452 different stocks.

As demonstrated by Da and Huang (2018), independent assessments of users are an important determinant for the accuracy of the consensus forecast as they increase the amount of private information in the consensus. With a social media or email account as the only entry barrier, we argue that everyone is able to become a member of the Sharewise community. As a consequence, Sharewise's social community faces a low risk of a systematic user selection bias (as, e.g., a minimum amount of invested capital would impose). As the idea of the wisdom of crowds or swarm intelligence is based on a large community of non-experts making more precise estimates than a small group of experts Galton, 1907; Lorge et al., 1958, Surowiecki, 2004, Yaniv and Milyavsky, 2007), we argue that the large Sharewise community with its limited barriers to entry represents 
an excellent setting to analyze the wisdom of crowds. $3^{3}$

Supporters of the efficient market hypothesis might be suspicious of our findings. Part of our contribution is to provide a theoretical argument explaining how the crowd consensus can have predictive power over market prices. We start by referring to the standard argument that the market is hard to predict because it is a good aggregator of information (Fama and French, 2015). Then, we observe that information does not flow freely in the financial market and that the main scope of a financial market is the redistribution of wealth, rather than correctly predicting changes in the fundamentals. We conclude by citing known results in statistics and computer science (Hannan, 1957; Foster and Vohra, 1999) demonstrating that the known qualitative features of the Sharewise consensus algorithm are specifically designed to improve upon the prediction accuracy of an algorithm with the qualitative feature of financial markets. The Sharewise consensus predicts future market prices better than the market because the Sharewise platform facilitates a transparent exchange of information and uses an aggregator algorithm which is optimized for prediction rather than the redistribution of wealth.

Even if the assessments made by the users of a large social community impart not only value-relevant news concerning the future development of the stock price but also information regarding stock-specific investor sentiment, this does not necessarily mitigate the value of these opinions. For example, as shown by Baker and Wurgler (2006), investor sentiment has implications for the cross-sectional returns of stocks with subjective valuation components. Similarly, De Long et al. (1990) show that noise-trader strategies, which are based on investor sentiment rather than rational information, are related to stock returns. In general, this investor sentiment is associated with retail investors Lee et al. 1991; Kumar and Lee, 2006; Barber et al., 2009) and can help explain return comovements (Kumar and Lee, 2006). Hence, even the subjective component of the information contained in user stock assessments that can be regarded as sentiment may

\footnotetext{
${ }^{3}$ However, we acknowledge that lower barriers to entry induce moral hazard and reduced self-restraint for users issuing stock assessments. Further, users are more likely to first consider the recommendations of their peers before issuing their own recommendations. Thus, they may be influenced by previously published opinions. Moreover, users may take advantage of the lower regulation and intentionally spread false information to manipulate other market participants.
} 
contain valuable information for future stock returns.

Research provides evidence for the implications of media attention and online activity for stock markets (see, e.g., Tetlock, 2007; Da et al., 2011; Engelberg and Parsons, 2011, Chen et al., 2014; Wang et al., 2015, Crawford et al., 2017). For example, Tetlock (2007) and Dougal et al. (2012) show that content provided by professional journalists has a significant effect on market prices. In addition, Da et al. (2011) introduce an online activity measure that captures direct investor attention and predicts future stock prices. More recently, Chen et al. (2014) and Wang et al. (2015) argue that investors increasingly rely on the decisions of their peers. The authors provide evidence for the usefulness of textual analysis of peer group comments that are disclosed on an online platform. From all of the content provided, investors can identify the valuable information that is relevant to stock prices to make good investment decisions. However, the economical implications of the difference between stock opinions in quantified or textual form are substantial. Changing authors, and associated writing styles, combined with verbalized content that leaves room for interpretation, may cause misunderstanding and erroneous investment decisions based on textual comments. Furthermore, users have no information regarding whether the information provided is already reflected in current security prices. Consequently, the predictive power of textual stock assessments depends on users' ability to extract the bits of valuable information. In contrast, standardized and clearly quantified results of stock analysis leave less room for misinterpretation and, therefore, increase the value of the information provided for investment decisions.

In our study, we analyze whether the cumulative knowledge of the crowd includes valuable stock-specific information that increases the explanatory power of stock performance models. Given that the crowd generates useful information, the stock assessments of the crowd offered on social investment platforms may help predict future stock performance and abnormal returns. We find that the stock opinions offered on the social media platform Sharewise contain information that helps to predict stock returns. We find that a portfolio based on social media opinions yields an excess return of 3.4\%. Our results are robust to crowds' level of consensus and high changes in expected stock prices and 
buy or sell recommendations. Moreover, we find that the explanatory power does not change when the crowd assesses high-volatility stocks, past poor performers, or stocks with limited media attention. Thus, we contribute by investigating a novel dataset on stock assessments disclosed on a social investment platform. In particular, we provide evidence that standardized crowd opinions contain valuable information for predicting stock returns. Our results are robust to controlling for momentum, short-term reversals, and the investor sentiment factor of Baker and Wurgler (2006).

One caveat of our study is that we do not have access to the individual recommendations of single users. Instead, our study relies on the aggregated consensus forecast, which is displayed on the Sharewise website. As a consequence, we are not able to distinguish between the forecast accuracy of individual users and the aggregation algorithm employed by Sharewise. However, we provide detailed information on the qualitative characteristics of the Sharewise algorithm and argue that knowledge of the individual recommendations and the exact specification of weights used in this algorithm is not necessary to show that the Sharewise consensus has predictive power over future prices.

The contribution of our study is the following: Our study extends the research on social media and stock markets and significantly differs from the existing literature, as we do not analyze specific trades but rather the stock-specific price forecasts of a crowd. In contrast to individual trades, we show that the stock opinions of the social crowd have explanatory power for the variation of stock returns in a large international sample across multiple markets. On Sharewise, users do not have to invest real money to share their assessments and investment recommendations. This enables them to more easily share information with the community without any constrains of liquidity or transaction costs. Yet, individual investors are able to benefit from the shared information by following the recommendations of the social crowd in their real investment transactions.

In the previous literature, for instance, Pan et al. (2012) rely on eToro data to study the roles of social mechanisms in a financial system. Analyzing individual trades on eToro between August 2010 and January 2012, the authors report that, on average, each trade lost approximately $2.8 \%$ in its position size. Similarly, Liu et al. (2014) analyze the trades 
on a large social trading platform and find large-scale empirical evidence of prospect theory (see also Pelster and Hofmann, 2018). Pelster and Breitmayer (2019) document that investors are more willing to take risks under the increased scrutiny of their peers, while Oehler et al. (2016) study the returns of wikifolio certificates. The authors find that these certificates do not outperform the market on average but show that the best-performing wikifolios earn significant short-term excess return. Most closely related to our study are the works by Adebambo et al. (2016); Avery et al. (2016); Chen et al. (2014); Da and Huang (2018); Jame et al. (2016); Tsukioka et al. (2018), and Wang et al. (2015). Wang et al. (2015) analyze the content of Seeking Alpha and StockTwits and report a low overall correlation between user assessments and stock performance. Only a small subset of experts from the social media platforms contribute valuable content for predicting future stock returns. However, Chen et al. (2014) report that verbalized stock assessments on Seeking Alpha contain strong explanatory power for future stock returns and earnings surprises. Studying the case of IPOs, Tsukioka et al. (2018) analyze message data from Yahoo! Japan Finance message boards and show that bullish investor sentiment positively affects IPO offer prices and initial returns. In contrast to these works, we study the value of quantified stock assessments as opposed to opinions in textual form. The studies by Adebambo et al. (2016) and Jame et al. (2016) document that crowd forecasts of Estimize.com are more accurate than traditional earnings consensus. In particular, Adebambo et al. (2016) provide evidence that the geographical proximity of forecasters to firm locations improves forecast accuracy. Analyzing the accuracy of earnings announcements forecasts, Da and Huang (2018) determine and randomize the information set users of Estimize.com and provide evidence that independent information sets of users increase the accuracy of the consensus forecast. In contemporaneous research, Jame et al. (2017) investigate the influence of increased forecast competition on short-term sell-side biases. In particular, the authors argue that crowds have less conflict of interest than professional analysts and help to discipline other market participants. Their results reveal that crowdsourced predictions reduce sell-side biases and improve sell-side forecast accuracy, thus contributing to market efficiency. In a similar strand of 
literature, collective trading imbalances are exploited to analyze the beliefs of crowds. Several studies from this strand show that retail investors trading imbalance correctly anticipates future stock returns (Kaniel et al., 2008, 2012; Kelley and Tetlock, 2013), supporting the wisdom of crowds hypothesis.

Further literature on the topic includes Doering et al. (2015), who discuss the institutional aspects of social trading platforms and argue that they are able to reduce information asymmetries between investors and portfolio managers. Moreover, the authors document that social trading platforms yield non-normal returns and experience high tail risk. They argue that these platforms offer high transparency, liquidity, and accessibility while providing access to hedge-fund-like returns. Pedraza and Pulga (2019) study the effects of peer benchmarking by institutional investors on asset prices and show that peer effects generate abnormal short-term returns followed by reversals in the next quarter, thereby generating excess stock return volatility. Finally, Pelster (2017) discusses the impact of social trading platforms on herding behavior and studies the determinants of influential traders on social media.

The remainder of our paper proceeds as follows. In Section 2, we introduce and describe our novel dataset. Section 3 describes our analysis of the relationship between crowd opinions and stock returns and presents our findings. A theoretical justification for the observed phenomenon is provided in Section 4 . Finally, we summarize our main contribution and discuss further research opportunities.

\section{Data}

This section introduces the novel dataset used in our empirical study, presents the choice of our main dependent and independent variables, and reports descriptive statistics for our data. Table A.1 in the appendix includes definitions and data sources for all dependent and independent variables. 


\subsection{Sample construction and data sources}

Our empirical investigations rely on data obtained from the social investment platform Sharewise. The website allows its users to deliver an opinion regarding the expected development of individual stocks. Specifically, users can voice buy or sell recommendations and price targets for all stocks traded worldwide. As platform host, Sharewise provides a transparent overview of all user opinions and aggregates the user recommendations into social crowd investment advice. Thus, opinions and investment recommendations are not made directly by Sharewise but by its registered community members. As Sharewise is not a registered broker, dealer, financial advisor, analyst, underwriter, or banker, the platform's self-reported purpose is to be used for information and reference purposes 4 Stock performance and firms' fundamental data shown on the platform are provided by Thomson Reuters. All information disclosed on Sharewise are accessible free of charge.

- Place Figure 1 about here -

Figure 1 shows the first view of the Sharewise welcome page. In a glance, the website reports price information for major stock market indexes around the world. Next, the welcome page reports the crowd consensus of the five stocks with the currently highest and lowest Potential, that is the price change expected by the crowd, for a selected stock market index. Users find company names, target prices suggested by the crowd, and the expected return for the top five highest and lowest Potential stocks according to the crowd. Scrolling down, the welcome page presents a list (see Figure 2 ) of the five stocks with the highest and lowest returns of the current trading day and the latest updates of the crowd consensus (see Figure 3). Furthermore, website visitors can find information about the stock of the day, a featured prediction from a selected user, a featured portfolio, and featured news on the welcome page.

- Place Figures 2 and 3 about here -

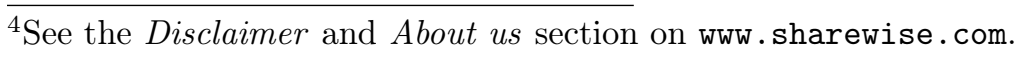


Selecting a specific instrument, for example an individual stock, the user can find more detailed information regarding that instrument (see Figure 4). Sharewise reports technical data such as the stock's name, ISIN, and the primary listing exchange, together with the firm's industry and home country. Furthermore, the website shows the current share price, the target price according to the crowd assessments, fundamental analysis, analysts' assessments and a cumulative target price. The company snapshot provides a summary of further key stock facts. Information regarding historical performance, beta, market capitalization, dividend yield, earnings ratio, and several other factors are presented in addition to a small chart depicting recent stock movements.

- Place Figure 4 about here -

In addition to the summary of key facts, more detailed information on the stock assessments is reported at the bottom of the website. First, an overall assessment that considers the fundamental analysis, the crowd assessment and the results provided by professional analysts is described in textual form. A detailed explanation of the fundamental analysis is followed by a report of the results of the crowd assessment and the most recent individual user contributions. The weighted community target price places greater weight on the predictions of users who have a high ranking-users who posses a proven track record of correct assessments in the past - than on the predictions of users who have a lower ranking. Moreover, still active buy predictions, in which the target price is lower than the current price of the stock, are not taken into account (and vice versa for sell predictions) $!^{5}$ Finally, the assessments of professional analysts are presented.

Users who wish to gather further firm-related information can obtain several figures from past financial statements (quarterly and annual statements), information about the most recent updates, the latest news coverage, and a press review. In addition, Sharewise provides detailed information on the stock assessments of individual community members. In addition to the target price and date, website visitors can revise the stock price at the ${ }^{5}$ The details on the aggregation algorithm are outlined on the Sharewise website (https://www. sharewise.com/us/help/about). Furthermore, a Sharewise employee confirmed the description on the aggregation algorithm in a telephone interview. 
time of the assessment, the expected return and the stock return since the assessment was published to obtain a better understanding of user recommendations. Below the key facts regarding the stock opinion, background information indicates whether the user has invested in the stock and the criteria on which the opinion is based. Finally, other users can comment on every stock assessment.

All individual opinions contribute to the aggregated crowd assessment of a stock. Figure 5 shows the front end of the platform, where users can contribute to the crowd assessment. The top of the page displays the current and most recent change in the stock price. Scrolling down, the website shows the current target price according to the crowd, the fundamental value of the stock, and the results of professional analyst valuations. This information is aggregated into an overall cumulated target price that is calculated by Sharewise. Next, users can submit a buy or sell recommendation and a specified target price to contribute to the crowd assessment. Additionally, they are able to select the timeframe of their assessment and can provide information on the basis for their assessment. Moreover, users can leave a statement on whether they have invested in the stock through a long or short position.

- Place Figure 5 about here -

To investigate whether the Sharewise community contributes valuable information for predicting future stock returns, this study focuses on the crowd consensus. Figure 6 shows the evolution of the crowd consensus together with the stock price evolution for four selected stocks from our sample.

- Place Figure6 6bout here -

Table 1 provides an example excerpt of the dataset obtained from Sharewise. The dataset includes an observation for each day on which at least one user submitted a recommendation for a given stock. An observation in our dataset contains the date, the ISIN of the underlying, a unique identifier, the number of users who submitted a recommendation to 
buy or sell the stock, and the average expected price as the target price of the crowd at the end of the day.

- Place Table 1 about here -

In total, from August 1, 2007, to July 15, 2015, Sharewise reports 14.9 million individual opinions on 10,452 stocks from 65 different countries..$^{6}$ The individual opinions are pooled to about 4.7 million opinion days with new crowd assessments, as on various days multiple new opinions regarding a single stock were shared while on other days no new opinions were shared 7

We supplement the dataset with daily stock prices (adjusted for dividends) from Thomson Reuters Datastream and calculate the return (Potential) as the price change expected by the crowd. To be specific, we define the Potential to equal (expected price - current price)/current price (adjusted for dividends). In the following, we will use Potential as our main proxy to measure the stock opinions of the Sharewise community. Additional variables, Total buy and Total sell, capture the total number of buy and sell recommendations, respectively, and are reflected in a stock's Potential. Furthermore, we calculate the ratio between total opinion and total buy opinion as a measure of the level of crowd consensus. Our argument is that the crowd's forecasts for stocks with low levels of consensus may be less reliable. Finally, for each stock-quarter, we aggregate the daily observations to one stock-quarter observation by taking averages.

We calculate buy-and-hold returns for six months and estimate six-month abnormal returns following the crowd assessment. Our calculation of abnormal returns is based on the difference between expected and actual returns. Expected returns are estimated using daily stock price data following the Fama and French (2015) five-factor asset pricing model. We include the benchmark return on a portfolio of small stocks minus the return on a portfolio of big stocks (SMB), the benchmark return on a portfolio of high

\footnotetext{
${ }^{6}$ The ten countries with the most stocks in our sample are as follows: United States 3699, Canada 1259, Germany 1186, France 743, United Kingdom 509, Australia 417, Japan 385, Honk Kong 249 , Switzerland 228, and Italy 113.

${ }^{7}$ On average, we have 448 days with new stock opinions shared for the stocks in our sample. For several stocks, we have a maximum of 2,141 days with new stock opinions while we only have a single day with new stock opinions for a few stocks as well.
} 
book-to-market ratio stocks minus the return on a portfolio of low book-to-market ratio stocks (HML), the benchmark return on a portfolio of stocks with robust profitability minus the return on a portfolio of stocks with weak profitability (RMW), and the benchmark return on a portfolio of low-investment stocks minus the return on a portfolio of high-investment stocks (CMA). The six-month buy-and-hold and abnormal return serve as dependent variables in our analysis.

In additional robustness checks, we rely on several other asset pricing models to estimate expected returns. First, we employ the Carhart four-factor model to control for momentum (Carhart, 1997). We also expand the Fama-French five-factor model expanded by the momentum factor proposed by Carhart (1997). Next, we estimate expected returns based on a Fama-French five-factor model expanded by a factor capturing short-term reversal. Short-term reversal has been shown to be a robust and economically significant phenomenon in the stock market (Da et al., 2014; Fama, 1965). Finally, we estimate expected returns based on a Fama-French five-factor model expanded by the investor sentiment factor proposed by Baker and Wurgler (2006). In two different market models, we employ both, the investor sentiment factor based on the standardized sentiment proxies, and the factor based on sentiment proxies orthogonalized with respect to macroeconomic indicators.

As reported by Ince and Porter (2006), stock prices in Datastream are subject to several minor data errors. To ensure that these errors do not influence the results of our study, we require all entities to have a minimum share price of $\$ 1$ to be included in our sample. For our analysis, we aggregate the daily data containing new stock opinions on a monthly and quarterly basis, respectively, by using the average. Stocks with no new opinions in a given quarter are not included in the final dataset.

\subsection{Control variables}

In addition to the variables discussed above, we include several control variables in our empirical analysis. First, we use stock market and fundamental firm data from Thomson 
Reuters Datastream and Worldscope, which is the data source of firms' fundamental data shown on Sharewise. To proxy for the size of each firm, we use the natural logarithm of a firm's total assets. The stock's book-to-market ratio, defined as the book value of common equity divided by the market value of common equity, serves as a proxy for the stock's valuation. We also consider the dividend yield of a stock. As further control variables, we estimate the Amihud measure of an individual stock's illiquidity, adjusted following the procedure proposed by Karolyi et al. (2012).

In addition to fundamental data, Sharewise provides recommendations of professional analysts that are based on data obtained from Thomson Reuters on its website. Therefore, we also control for professional analyst opinions obtained from Thomson Reuters Datastream in our analysis. The professional analyst assessments capture the aggregated analyst opinion regarding the expected return. To control for the ease of the valuation of stocks, we estimate stock volatility. We argue that firms with stocks that exhibit high levels of volatility are difficult to value. We estimate a conditional volatility model using a $\operatorname{GARCH}(1,1)$ model and daily data. In addition to the volatility of stock returns, we also estimate the volatility of stock opinions transmitted through Sharewise using daily data. High volatility in stock opinion indicates that the crowd often changes its forecasts, which impedes basing investment decisions on the forecasts. One might expect that stocks with high stock volatility also exhibit high levels of volatility in stock opinions. However, we observe significantly lower volatility for opinions than for stock return data, and the correlation between the two volatility measures is 0.153 and statistically significantly different from zero at the $1 \%$ level. This indicates that the two volatility measures do not capture the same effect. Next, as an additional proxy for investor attention introduced by Da et al. (2011), we include the stock-related Google search volume index obtained from Google trends in our analysis. The Google search volume allows us to identify the time-variation in common investor attention within each stock. In contrast, the number of predictions also captures the cross-sectional variation of investor attention but is limited to the attention on the Sharewise platform. Finally, to control for firm-specific 
news events, we include data on earnings surprises 8 provided by Thomson Reuters and an aggregated news sentiment variable provided by Quandl. The Quandl Alpha One Sentiment Article Sentiment is based on articles aggregated from over 20 million news sources. We have to restrict our sample when employing the news sentiment variable, because the Quandl Alpha One Sentiment data is not available for all countries in our sample. In robustness checks, we also consider the distance of the current share price from the 52-week high and the 52-week low in our analysis.

\subsection{Descriptive statistics}

In the following section, we provide some summary statistics for our main data. Table 2 presents the mean, standard deviation, skewness, and kurtosis, together with median, minimum and maximum values for the total number of opinions shared on Sharewise, the total number of buy recommendations, the total number of sell recommendations, and the Potential. Similar to the Potential, summary statistics on analyst opinions are reported. Moreover, the table presents summary statistics for our dependent variables, the six-month buy-and-hold return and the abnormal return. The statistics show that users are more likely to recommend "buy" rather than "sell". For each stock-quarter, we observe about 140 buy recommendations, as opposed to about 30 sell recommendations. At the same time, however, a separation of Potential with respect to community buy and sell recommendations reveals an overall higher number of sell recommendations. Thus, on average, community sell recommendations are based on fewer single user recommendations than community buy recommendations. This observation is consistent with previous observations documented in the literature: Muchnik et al. (2013) and Tang et al. (2017) document a positivity bias against negative sentiment. While this positivity bias is reflected in the mere number of recommendations, the average predicted return based on the weighted community target price amounts to about $-.048 \%$ (median -.062 ). Thus, the weighting algorithm, on average, outweighs the positivity bias and yields a negative

\footnotetext{
${ }^{8}$ We do not have data on earnings surprises for all our observations and, thus, can only consider a smaller sample when controlling for earnings surprises.
} 
predicted return. Average realized returns are .052 .

- Place Table 2 about here -

Table 3 reports the pairwise correlations between selected variables included in our analysis. Notably, we observe a high correlation between the number of buy and sell recommendations. One possible explanation for this finding is that some stocks receive more attention than others. Moreover, the opinions of Sharewise users do not reflect a clear-cut consensus for these stocks, which yields high correlation between the number of buy and sell recommendations. Most other correlations are low.

\section{Stock returns and crowd assessments}

This section presents and discusses the main empirical findings of our study. First, we study the price performance of Potential stocks. Then, we investigate whether quantified crowd assessments transmitted through a social investment platform help to predict future stock returns. Moreover, we conduct several subsequent analyses. First, we distinguish various crowd characteristics that may affect the explanatory power of the stock assessments. Second, we examine stocks that exhibit different return and investor attention characteristics.

\subsection{Implications of Sharewise crowd opinions for stock prices}

First, we present an analysis of the time series of returns of stocks with large Potential indicated by the Sharewise crowd minus stocks with low Potential for evidence of any excess returns, after adjusting for established predictors of stock returns. For the analysis, we aggregate the daily data containing new stock opinions on a monthly basis by using the average. Each regression is estimated with the monthly aggregated data over the 96-month sample period from August 2007 to July 2015. 
First, we estimate the CAPM,

$$
\operatorname{DIFPOT}_{t}=\alpha+\beta(M k t-R F)+\varepsilon_{t},
$$

for $t=1, \ldots, 96$, where DIFPOT is the return of a portfolio that is long stocks with the largest potential (upper third) and short stocks with the lowest potential (lower third) as indicated by the Sharewise crowd and $M k t-R F$ is the excess return of the market portfolio (see Hong and Kacperczyk, 2009, for a similar approach). Portfolios are adjusted monthly. We are especially interested in the $\alpha$ of the regression that represents the excess return of the portfolio created based on the recommendations of the Sharewise crowd. Table 4 (Model (1)) presents the results of our regression analysis. The positive alpha indicates an excess return of $3.3 \%$. The large magnitude of the excess return may be explained by the nature of the platform. Naturally, individuals are more likely to provide a forecast for a stock, if they expect large absolute returns, and not, if they expect returns of only small magnitudes. As a result, if forecasts are approximately correct, on average, realized returns on the strategy based on these forecasts, will be large as well.

In addition to the CAPM, we consider other established asset pricing models, such as the Fama and French (2015) five-factor asset pricing model, the Carhart four-factor model, a Fama-French five-factor model expanded by the momentum factor proposed by Carhart (1997), Fama-French five-factor models expanded by factors to control for short-term or long-term reversal, and Fama-French five-factor models expanded by investor sentiment factors proposed by Baker and Wurgler (2006). The additional results presented in Table 4 support the estimated excess return of approximately $3.3 \%$ of a portfolio based on Sharewise recommendations.

- Place Table 4 about here - 


\subsection{Sharewise crowd opinions and buy-and-hold returns}

Crowd consensus reflects the expectations of future stock price developments. As the longest time period considered on Sharewise is six months, target prices should materialize within this horizon. To analyze the relationship between crowd opinions and stock returns, we calculate six-month buy-and-hold returns for each investment opinion and lag the crowd opinion (Potential) transmitted through the Sharewise platform by six months. Table 5 (Panel A) reports the results of our fixed-effects panel data regressions on sixmonth buy-and-hold returns using quarterly data. Our final quarterly dataset contains 73,015 stock-quarter observations. We rely on quarterly data for the panel regressions as balance sheet information is not available at a monthly frequency. We conduct several sets of panel data regressions to model the determinants of stock performance and shed light on the relationship between crowd opinions and stock returns. We apply a panel regression approach with stock and time fixed effects using robust standard errors clustered at the individual stock level to mitigate possible issues resulting from heteroskedasticity and serial correlation. We exploit the within-variation of crowd opinions to account for the fact that a sell recommendation of a given stock in 2007 may turn into a buy recommendation until 2015 or vice versa.

- Place Table 5 about here -

In our first two regression models, using the full sample with and without control variables, we observe a positive coefficient for Potential. The coefficient is significant at the $0.1 \%$ level. We perform subsample tests to examine the explanatory power of crowds with different characteristics. To investigate the role of the crowd consensus regarding investment choices, we distinguish two subsamples. The low-consensus subsample includes recommendations for which at least $25 \%$ of user opinions recommend a different investment strategy (sell or buy) than the majority. The high-consensus subsample consists of all stock opinions for which all user recommend the same strategy (sell or buy). The results of our regression analysis reveal a slightly larger coefficient and $t$-statistic on 
Potential for high-consensus than for low-consensus stocks. However, that the coefficient is also significantly positive for low-consensus stocks indicates that the consensus forecast is rather reliable. According to a $t$-test, the two Potential coefficients are statistically different from each other at the $0.1 \%$ level. The explanatory power of the forecasts is not driven by the "simple" cases, where everybody agrees that a stock has a high Potential and will easily increase in value over time.

In Model (5), we restrict our sample to stocks with high volatility in stock opinions (top quartile). Stocks with high volatility in stock opinions may decrease the explanatory power of crowds' stock assessments and prevent their successful utilization in investment decisions. However, while the regression results indicate that indeed the coefficient is significantly smaller than in the full sample (according to a $t$-test), it is nonetheless still significantly different from zero. Thus, large target price adjustments over time do not seem to affect the relationship between crowd assessments and stock returns.

Finally, we restrict our attention to those stocks with strong sell advice from the crowd. As the majority of recommendations indicate positive Potential, the explanatory power may differ when the crowd expects decreasing prices. In Model (6), we consider those stocks that exhibit the $25 \%$ highest expected price decrease. Again, our regression results do not change dramatically.

Next, we consider several subsamples constructed with respect to stock characteristics. In Panel B of Table 5, we begin our analysis with stocks that exhibit high return volatility (top quartile). We argue that those stocks are more difficult to value. Conversely, lowvolatility stocks are easier to value, and the valuation may contain fewer subjective errors. Yet, we observe that the relationship between Potential and stock returns holds for both subsamples; albeit with statistically different coefficients, according to a $t$-test. Second, we only consider stocks in the bottom return quartile, that is, stocks with poor past performance. Third, we only consider stocks that receive a relatively low level of investor attention. With low investor attention, users may be less well-informed. Consequently, their stock assessments may lack in value. We consider times where a given stock receives little and high investor attention, measured in terms of Google search volume (Model (4) 
and Model (5)). In line with our argument, we observe a significantly larger coefficient on Potential for high attention stocks compared to low attention stocks ( $p$-value of $t$-test $<$ 0.01). Next, we consider stocks that receive little and high attention compared to other stocks, based on the number of Sharewise predictions (Model (6) and Model (7)). Again, we observe a larger coefficient on Potential in the high attention group. A $t$-test indicates that coefficients are different at the $0.1 \%$ level. Yet, we can state that in all subsamples considered, we confirm our main results.

Finally, it is possible that the arrival of firm-level news is driving both the investors' predictions and future returns. For example, the most important news event for many firms is the quarterly earnings announcement which leads to a post earnings announcement drift in many countries (Hung et al. 2015). In Model (8) we control for earnings surprises. The analysis supports our findings. To control for other news events, we rely on Quandl Alpha One Sentiment Data (News sentiment). Model (9) provides evidence that the consensus is not simply correlated with firm-level news that has predictive power.

Furthermore, in unreported robustness checks, we add the distance from the stock's 52week high and 52-week low as additional control variables. The results for our variable of interest (Potential) remain nearly unchanged: The coefficient on Potential is .096, while the coefficients on the difference to 52-week low is positive and the coefficient on the difference to 52 -week high is negative. All coefficients are statistically different from zero.

\subsection{Sharewise crowd opinions and abnormal returns}

In the previous section, we provided some evidence that the stock opinions transmitted through the social media platform Sharewise are positively related to stock returns. However, the stock opinions could simply reflect expected returns and thus not provide any additional insights. To test whether this is the case, we study the relationship between stock opinions (Potential) and abnormal returns. Again, we apply a panel regression approach with stock and time fixed effects using robust standard errors clustered at the individual stock level. 
Table 6 reports results of our fixed-effects panel regressions on abnormal returns. Our first models (Panel A) (without and with control variables) show a positive relationship between stock opinions (Potential) and abnormal returns. The coefficient is statistically significantly different from zero at the $0.1 \%$ level. Similar to Section 3.2, we conduct several subsample tests to examine the explanatory power of Potential under different circumstances. Again, we separate stocks with low and high crowd consensus (Models (3) and (4); coefficients on Potential are different at the $0.1 \%$ level). Next, we only include stocks with high changes in the stock opinions of the crowd (top quartile, Model (5)), and only consider stocks with high sell Potential (top quartile) according to the crowd (Model (6)). For all subsamples, the message of our results remains the same.

- Place Table 6 about here -

In Panel (B) of Table 6, subsamples are constructed with respect to different stock characteristics. First, we restrict our sample to stocks with high and low volatility (top quartile, Model (1) and bottom quartile, Model (2); coefficients are different from each other at $0.1 \%$ level). Both coefficients are significantly positive. Next, we build subsamples for stocks with poor past performance (bottom quartile of performance, Model (3)), and for stocks with the lowest and highest investor attention, measured in terms of Google search volume (bottom quartile, Model (4) and top quartile, Model (5); coefficients are different at $0.1 \%$ level). In addition, we build subsamples on the number of Sharewise predictions (bottom quartile, Model (6) and top quartile, Model (7); $p$-value of $t$-test $<0.001$ ). Even though the coefficients on the subsamples differ somewhat in size, we obtain statistically significant positive coefficients on Potential in all cases. Thus, the observed relationship between crowd stock assessments and abnormal stock returns is robust to different stock return characteristics and levels of investor attention.

In the same manner as described in Section 3.2 we control for the impact of firm-level news. We control for earnings surprises in Model (8) and for general firm-level news events employing Quandl Alpha One Sentiment Data in Model (9) and confirm the results of our main analysis. 


\subsection{Robustness checks}

We perform a series of additional robustness. First, we split our sample to examine the explanatory power of target prices across countries. We separately examine the explanatory power for the countries with the most stocks in our sample. Specifically, we separately estimate Model (2) of Table 6 (Panel A) and restrict the sample to stocks from a given country. While we observe a positive significant relationship between Sharewise target prices and abnormal returns for the United States, Canada, Germany, France, and Austrialia, the results are not robust for the United Kingdom, where we observe a coefficient that is statistically not different from zero (untabulated results).

Second, we perform a series of additional robustness checks by estimating expected returns based on a set of different market models. We perform these robustness checks to control for the possibility that the predictive power of Sharewise target prices just captures welldocumented patterns in stock prices such as momentum or investor sentiment.

For example, it may be possible that Sharewise users form target prices by extrapolating from past returns. This would lead to the predictive power of target price implied expected returns, if past returns positively predict future returns in mid-term horizon. Consequently, in this case crowd forecasts would just capture momentum. We can rule this possibility out by estimating expected returns based on the four-factor model proposed by Carhart (1997) or a Fama-French five-factor model expanded by the momentum factor and then repeating the analysis described in Section 3.3. We do not tabulate results to preserve space. However, our estimates remain virtually unchanged.

Another alternative explanation could be that target prices only contain noise and are negatively correlated with past prices. Given short term reversal in stock returns, past prices negatively predict future returns, which in turn explains the positive relation between crowd forecasts and future returns. Thus, crowd forecasts would not contain additional information beyond short term reversal of past returns. We control for this possibility by estimating expected returns based on a Fama-French five-factor model expanded with a short-term reversal factor. Our analyses provide evidence for the explanatory power also 
in this case.

Finally, Sharewise crowd forecasts may capture no additional information beyond investor sentiment. We also check for this possible explanation by estimating expected returns based on a Fama-French five-factor model, expanded with the Baker and Wurgler (2006) investor sentiment factor. Our results hold in this case as well.

In addition to different specifications to estimate expected returns, we also perform several subsample analysis in order to verify the robustness of our results. First, we split our sample into two periods of equal length. We can confirm our results for both sub-periods. Similarly, we repeat our analysis focusing on time periods of high market volatility and low market volatility. Our results hold in both settings.

\section{Theoretical justification for crowd consensus}

\section{accuracy}

In this section, we explain how Sharewise's collective predictions become accurate. Our arguments are inspired by the vast literature on efficient markets (Malkiel and Fama, 1970) which identifies three mechanisms concurring to market efficiency.

First, financial markets can be efficient because they aggregate private information. Modeling the heterogeneity of opinions as only driven by heterogeneity in traders' private information and assuming common knowledge, markets are informationally efficient because each trader learns the private information of the other traders from prices. Even if traders have access to exclusive, private information and have different opinions before trading, in equilibrium they must hold the same, most informed opinion because all private information is revealed Aumann, 1976; Grossman, 1976, Radner, 1979; Geanakoplos and Polemarchakis, 1982).

Second, equilibrium prices become accurate because of natural selection. According to the market selection hypothesis, traders with inaccurate beliefs progressively lose wealth to traders whose beliefs are accurate Alchian, 1950, Friedman, 1953). Therefore, markets 
become efficient because equilibrium prices eventually reflect the probabilistic views only of the accurate traders that survive (Sandroni, 2000).

Third, the wisdom of the crowd argument, according to which an average of users opinions can deliver more accurate predictions than that of every single user because errors cancel out Galton, 1907).

Here we argue that the same mechanisms contribute to Sharewise's crowd consensus' accuracy. Moreover, the Sharewise crowd consensus can have predictive power over market prices because the platform is constructed to make use of these mechanisms more efficiently than financial markets. Unlike the market, Sharewise's platform facilitates a transparent exchange of information, it uses an aggregator algorithm which is optimized for prediction rather than the redistribution of wealth and it provides an environment in which users' prediction errors are likely to cancel out.

\subsection{Information aggregation}

A standard argument for market efficiency is that users can infer private information from prices. By participating in financial markets each user loses his information advantage and gains the collective wisdom of all market participants. As a result, equilibrium prices are efficient because they reflect all private information.

While the conditions under which prices perfectly reveal private information are demanding and unlikely to hold in financial markets, the Sharewise platform is designed to work as a transparent information aggregator (see Section 2 for details). Rather than tackle the arduous task of reconstructing private information from market prices, Sharewise's users have direct access to each other opinions. As the platform host, Sharewise not only provides easy access to publicly available information but also gives a transparent overview of all user opinions and aggregates the user recommendations into a price target. 


\subsection{Market selection}

According to the market selection hypothesis, users with inaccurate beliefs progressively lose their wealth to users whose beliefs are more accurate. Eventually, asset prices become accurate because they exclusively represent the probabilistic view of those traders that survive the selection process. One of the limitations of the selection argument is that it requires a closed system: if new traders keep entering the market (noise traders), or traders leave the market after a certain amount of time, there is no guarantee that equilibrium prices will ever become efficient.

Sharewise's crowd consensus is a rank-weighted average of user recommendations, where users' rankings depend on the accuracy of their past predictions and the length of their prediction history. Because a user's ranking depends on past accuracy, Sharewise's aggregation algorithm selects for accurate traders in a way that is qualitatively similar to market selection $9^{9}$ Moreover, giving more weight to those users with a longer prediction history is a way to mitigate the problem of noise traders, thus increasing the accuracy and reliability of crowd consensus.

Although we were not given the details of Sharewise's algorithm, we can describe its qualitative feature and rationale. The main difficulty is to construct the ranking system in such a way to be optimal with respect to prediction accuracy. To gain intuition, we start our discussion in a completely controlled setting where known results from robust learning can be directly applied Cesa-Bianchi and Lugosi, 2006, Cover and Thomas, 2012). Next, we discuss modifications tailored to address Sharewise's prediction task. We do not claim that Sharewise's algorithm coincides with the one we describe. Our discussion is simply meant to illustrate the qualitative features of Sharewise's algorithm to support our empirical findings.

Models in the market selections literature have shown that equations governing equilibrium prices are qualitatively similar to the algorithm described below Blume and Easley, 2009; Massari, 2016). However, unlike Sharewise's algorithm, the "market algorithm" is

\footnotetext{
${ }^{9}$ See section 2.1 for details on the aggregation algorithm; also, the interested reader is referred to the Sharewise website (https://www.sharewise.com/us/help/about) for additional information.
} 
not calibrated for good predictions. In financial markets, wealth-shares evolution and the weight of individual opinions on equilibrium prices are vastly affected by individual preferences in a way that does not need|to be optimal for price accuracy. On the contrary, Sharewise's algorithm disregards user preferences and combines their opinions with the sole goal of prediction accuracy.

Specifically, the Sharewise algorithm can improve over the "market algorithm" in two dimensions. First, while each user in the market invests to maximize his specific utility function, the Sharewise algorithm uses a unique accuracy criterion to assign weights. This makes user predictions comparable, eliminating those biases due to heterogeneity in user preferences. Second, unlike the market, Sharewise's algorithm has the flexibility to optimally choose its learning rate and discounting parameters.

\subsubsection{The platonic world}

To a first-order approximation, Sharewise's prediction problem can be made consistent to the setting of expert predictions by Cesa-Bianchi and Lugosi (2006). There is a finite number of users ("experts") which make a series of price recommendations. Given a predetermined criterion for accuracy (e.g. sum of squared error, or Sharpe ratio), Sharewise's goal is to design a rule which dynamically combines user recommendations into a consensus with good out-of-sample accuracy performance.

We focus on those algorithms that possess the minimum regret property (Hannan, 1957; Foster and Vohra, 1999). That is, with the property that as the number of recommendations increases, the average collective recommendation is as accurate as the average prediction of the most accurate user with hindsight (e.g. Blackwell et al., 1956; Vovk, 1990, Cover and Thomas, 2012). Focusing on regret, rather than accuracy, allows to derive results that are independent of the data generating process that governs prices and user predictions. Minimum regret is closely related to prediction accuracy and consistency. Under standard assumptions about users' loss functions and about the processes governing prices and user predictions, algorithms with minimal regret are consistent Grünwald, 2007). 
Let us start by rephrasing a known result: if the platform has (a) a finite number of users, $\mathcal{I}$, (b) which make recommendations at the same time for the same assets, (c) the ranking function is monotone in past accuracy, and $(\mathrm{d})$ the crowd consensus is an (exponentially) rank-weighted average of user recommendations, then, the crowd consensus has the minimum regret property.

Formally, let $\left\{q_{\tau}^{s}\right\}_{\tau=1}^{t-1},\left\{q_{\tau}^{i}\right\}_{\tau=1}^{t-1},\left\{Q_{\tau}\right\}_{\tau=1}^{t-1}$ be the collective price target, user $i$ recommendation, and the sequence of prices, respectively. Let $d_{t}^{i}\left(q_{t}^{i}, Q_{t}\right):=d_{t}^{i}$ be a convex, monotone measure of user accuracy, and let the collective price target be an exponentially rank-weighted average of user recommendations: $q_{t}^{s}=\sum_{i \in \mathcal{I}} w_{t}^{i}\left(\left\{d_{\tau}^{i}\right\}_{\tau=1}^{t-1}\right) q_{t}^{i}$, with $w_{t}^{i}\left(\left\{d_{\tau}^{i}\right\}_{\tau=1}^{t-1}\right)=\frac{e^{\eta \sum_{\tau=1}^{t} d_{\tau}^{i}}}{\sum_{j \in \mathcal{I}} e^{\eta \sum_{\tau=1}^{t} d_{\tau}^{j}}}$. Where $\eta \in(0, \infty)$ is a free parameter that regulates the convergence rate of the community predictions to the predictions of the most accurate user in the past. Then, the following theorem holds.

Theorem 1. Under $a$-d and $\forall \eta \in(0, \infty)$, the (exponentially) rank-weighted average recommendation is eventually at least as accurate as the average recommendation of the most accurate user.

$$
q_{t}^{s}=\sum_{i \in \mathcal{I}} w_{t}^{i}\left(\left\{d_{\tau}^{i}\right\}_{\tau=1}^{t-1}\right) q_{t}^{i} \quad \Rightarrow \quad \forall i, \lim _{t \rightarrow \infty} \frac{1}{t} \sum_{\tau=1}^{t} d_{\tau}^{i}-d_{\tau}^{s} \geq 0
$$

Proof. Known result, e.g. Vovk (1990) or Cesa-Bianchi and Lugosi (2006).

Note that, no assumptions are made on the price process or on users' probabilistic models. Sharewise's crowd consensus predictions are, on average, at least as accurate as the predictions of the most accurate user. The result holds for every sequence of prices and are irrespective of the probabilistic models employed by users to make predictions. If we further assume that the true probability governing prices and the subjective probabilities governing user recommendations follows some ergodic process, then Theorem 1 ensures that the crowd consensus converges in average to the prediction of the most accurate user.

Corollary 2. Under the assumptions of Theorem 1, if we further assume that user predic- 
tions and equilibrium prices are ergodic, then next-period recommendations are eventually as accurate as the recommendation of the most accurate user.

Proof. Under the stated assumptions, bounded regret implies consistency (Cesa-Bianchi and Lugosi, 2006).

\subsubsection{A step in the real world}

In the previous section, we have shown that in an artificial setting, the use of a rankingweighted-average prediction guarantees good average predictions. The real world, however, is a much more interesting environment: users do not make infinitely many predictions, they do not make the same number of predictions, they do not make predictions at the same time, and the number of users making predictions is not constant. Of our initial assumptions, only (c) and (d) hold in practice. Accordingly, our platonic result is altered as follows. (i) The rank-weighted prediction never identifies a unique most accurate user and (ii) the length of the prediction history should be taken into consideration.

These limitations can be mitigated by choosing an appropriate value for the $\eta$ parameter. By recursively searching for the optimal value of the $\eta$ parameter, it is possible to determine the best weight to give to users as a function of their past performance. This approach is known to deliver predictions with the minimum regret property and a super-

efficiency property (Safe Bayesian, by Grünwald and van Ommen (2017) and Massari (2017); Dindo and Massari (2019)). It delivers predictions that are safe - at least as accurate as the most accurate user - and super-efficient - its predictions can be even more accurate than the most accurate user.

Specifically, if the environment is stable enough, Sharewise's algorithm can be calibrated to ensure an optimal tradeoff between the diversity of opinions brought in by users with short prediction histories and the proven reliability of those users with longer prediction histories. Intuitively, it is reasonable to give more weight to the prediction of a user that has a record of 900 correct predictions over a total of 1000, rather than to one with a record of 10 correct predictions out of 10 . The former is less accurate but more reliable. 
As a concluding remark, we want to highlight that the parameters the algorithm optimally choses are not statistical parameters calibrated to match some regularities (e.g. moments) of the data. They are the parameters governing the rate at which the algorithm converges to the most accurate model. As such, this optimization improves Sharewise's community forecast accuracy, rather than making the estimates fragile to out-of-sample performance.

\subsection{Wisdom of the crowd}

In the previous section, we argued that Sharewise's crowd consensus is a non-degenerate rank-weighted average of users' opinion. The ranking helps the wisdom of the crowd argument by giving less weight to the prediction of users that are less reliable because they have bad past record or not enough predictions. However, it does not prevent those opinions to be systematically biased. For example, if all users were optimistic, their collective opinion is also optimistic. Further, the prediction of users with low rank can still have a large impact on collective predictions, if their recommendations are very different from the average.

Under regularity conditions, these problems could be addressed adjusting the aggregator algorithm. However, this correction would comport a substantial manipulation of users' opinions which is against the spirit of the platform.

Empirically, we find that there is no need to modify the aggregator algorithm. User recommendations do not display systematic biases or excessive variance. A natural conjecture for this lucky accident is that user recommendations are affected (anchored) by the current level of stock prices and past trends. Anchoring, which from the individual perspective is a "bias", improves crowd consensus' accuracy because it helps reducing the volatility in the predictions — thus working as a "shrinkage estimator" (Stein et al., 1956). 


\section{Conclusion}

In this paper, we investigate the relationship between stock-specific crowd opinions transmitted through social media and stock performance. To understand the relevance of information shared on social media for stock returns is of importance for investors, regulators, and providers of financial services, for example, because investors may execute trades according to these recommendations. We analyze stock-specific crowd opinions utilizing an innovative, unique dataset that contains more than 14.9 million individual stock assessments for 10,452 stocks for the period from August 1, 2007, to July 15, 2015. Exploiting this dataset, we find a positive relationship between crowd stock opinions and stock returns. In particular, we observe an excess return of $3.4 \%$ for a portfolio based on Sharewise recommendations. Thus, our study provides evidence that the cumulative knowledge of the crowd includes some valuable information that increases the explanatory power of stock return models. We offer a theoretical foundation for our evidence based on the literature on efficient markets. We argue that financial markets are subject to institutional restrictions which do not exist on the platform. Therefore, by employing an aggregator algorithm that is optimized for prediction rather than the redistribution of wealth, the Sharewise crowd can contribute to explaining stock returns.

The aggregator algorithm also mitigates the impact of the positivity bias previously documented in the literature (Muchnik et al., 2013, Tang et al., 2017) and evident in the number of observations provided on Sharewise. While Tang et al. (2017) document that the misinformation due to the bias leads to underperformance, the weighted community recommendations in our study can contribute to explaining abnormal returns.

We provide evidence for the explanatory power of crowd opinions for future stock returns and abnormal returns in different scenarios. Even if the social investment platform users do not reach consensus, the aggregated stock opinions provide valuable information. The relationship is also robust to large changes in stock opinions over time, stocks that are difficult to value, and stocks that only receive a low level of investor attention. Similarly, our results suggest that the predictive power is not driven by momentum, short-term rever- 
sal, or investor sentiment. Our results also hold across different countries and economies with different levels of strength. Thus, our study provides evidence supportive of the concept of crowd intelligence introduced by Galton (1907) (see also Surowiecki, 2004) in the context of investment decisions on stock markets.

Our paper contributes to the growing literature on social media investment platforms. The influence of social media on investment decisions has increased significantly and is expected to increase further in the future. Our paper shows that this growing attention is reasonable, as the information offered on these platforms contributes to explaining future abnormal stock returns.

\section{References}

Adebambo, B.N., Bliss, B., Kumar, A., 2016. Geography, diversity, and accuracy of crowdsourced earnings forecasts. Working Paper .

Alchian, A.A., 1950. Uncertainty, evolution, and economic theory. The Journal of Political Economy 58, 211-221.

Aumann, R.J., 1976. Agreeing to disagree. The annals of statistics 4, 1236-1239.

Avery, C.N., Chevalier, J.A., Zeckhauser, R.J., 2016. The "caps" prediction system and stock market returns. Review of Finance 20, 1363-1381.

Baker, M., Wurgler, J., 2006. Investor sentiment and the cross-section of stock returns. The Journal of Finance 61, 1645-1680.

Barber, B.M., Odean, T., 2000. Trading is hazardous to your wealth: The common stock investment performance of individual investors. The Journal of Finance 55, 773-806.

Barber, B.M., Odean, T., Zhu, N., 2009. Do retail trades move markets? The Review of Financial Studies 22, 151-186.

Blackwell, D., et al., 1956. An analog of the minimax theorem for vector payoffs. Pacific Journal of Mathematics 6, 1-8.

Blume, L., Easley, D., 2009. The market organism: long-run survival in markets with heterogeneous traders. Journal of Economic Dynamics and Control 33, 1023-1035.

Bollen, N.P.B., Busse, J.A., 2004. Short-term persistence in mutual fund performance. The Review of Financial Studies 18, 569-597.

Busse, J.A., Goyal, A., Wahal, S., 2010. Performance and persistence in institutional investment management. The Journal of Finance 65, 765-790.

Carhart, M.M., 1997. On persistence in mutual fund performance. The Journal of Finance $52,57-82$. 
Cesa-Bianchi, N., Lugosi, G., 2006. Prediction, learning, and games. Cambridge university press.

Chen, H., De, P., Hu, Y.J., Hwang, B., 2014. Wisdom of crowds: The value of stock opinions transmitted through social media. The Review of Financial Studies 27, 13671403.

Cover, T.M., Thomas, J.A., 2012. Elements of information theory. John Wiley \& Sons.

Crawford, S., Gray, W., Johnson, B.R., Price III, R.A., 2017. What motivates buy-side analysts to share recommendations online? Management Science 64, 2473-2972.

Da, Z., Engelberg, J.E., Gao, P., 2011. In search of attention. The Journal of Finance 66, 1461-1499.

Da, Z., Huang, X., 2018. Harnessing the wisdom of crowds. Working Paper .

Da, Z., Liu, Q., Schaumburg, E., 2014. A closer look at the short-term return reversal. Management Science 60, 658-674.

De Long, J., Shleifer, A., Summers, L., Waldmann, R., 1990. Noise trader risk in financial markets. Journal of Political Economy 98, 703-738.

Dindo, P., Massari, F., 2019. The wisdom of the crowd in dynamic economies. University Ca'Foscari of Venice, Dept. of Economics Research Paper Series No 17.

Doering, P., Neumann, S., Paul, S., 2015. A primer on social trading networks: Institutional aspects and empirical evidence. Working Paper.

Dougal, C., Engelberg, J., Garcia, D., Parsons, C.A., 2012. Journalists and the stock market. The Review of Financial Studies 25, 639-679.

Engelberg, J.E., Parsons, C.A., 2011. The causal impact of media in financial markets. The Journal of Finance 66, 67-97.

Fama, E.F., 1965. The behavior of stock market prices. The Journal of Business 38, $34-105$.

Fama, E.F., French, K.R., 2015. A five-factor asset pricing model. Journal of Financial Economics 116, 1-22.

Foster, D.P., Vohra, R., 1999. Regret in the on-line decision problem. Games and Economic Behavior 29, 7-35.

Friedman, M., 1953. Essays in positive economics. volume 231. University of Chicago Press.

Galton, F., 1907. Vox populi. Nature 75, 450-451.

Geanakoplos, J.D., Polemarchakis, H.M., 1982. We can't disagree forever. Journal of Economic Theory 28, 192-200.

Grossman, S., 1976. On the efficiency of competitive stock markets where trades have diverse information. The Journal of Finance 31, 573-585. 
Grünwald, P., van Ommen, T., 2017. Inconsistency of bayesian inference for misspecified linear models, and a proposal for repairing it. Bayesian Analysis 12, 1069-1103.

Grünwald, P.D., 2007. The minimum description length principle. MIT press.

Hannan, J., 1957. Approximation to bayes risk in repeated play. Contributions to the Theory of Games 3, 97-139.

Hommes, C., Sonnemans, J., Tuinstra, J., van de Velden, H., 2005. Coordination of expectations in asset pricing experiments. The Review of Financial Studies 18, 955980.

Hong, H., Kacperczyk, M., 2009. The price of sin: The effects of social norms on markets. Journal of Financial Economics 93, 15-36.

Hung, M., Li, X., Wang, S., 2015. Post-earnings-announcement drift in global markets: Evidence from an information shock. The Review of Financial Studies 28, 1242-1283.

Ince, O., Porter, R., 2006. Individual equity return data from Thomson Datastream: Handle with care! The Journal of Financial Research 29, 463-479.

Jame, R., Johnston, R., Markov, S., Wolfe, M.C., 2016. The value of crowdsourced earnings forecasts. Journal of Accounting Research 54, 1077-1110.

Jame, R., Markov, S., Wolfe, M.C., 2017. Does crowdsourced research discipline sell-side analysts? SMU Cox School of Business Research Paper 18.

Kaniel, R., Liu, S., Saar, G., Titman, S., 2012. Individual investor trading and return patterns around earnings announcements. The Journal of Finance 67, 639-680.

Kaniel, R., Saar, G., Titman, S., 2008. Individual investor trading and stock returns. The Journal of Finance 63, 273-310.

Karolyi, A., Lee, K.H., van Dijk, M.A., 2012. Understanding commonality in liquidity around the world. Journal of Financial Economics 105, 82-112.

Kelley, E.K., Tetlock, P.C., 2013. The journal of finance. How Wise Are Crowds? Insights from Retail Orders and Stock Returns 68, 1229-1265.

Kumar, A., Lee, C.M., 2006. Retail investor sentiment and return comovements. The Journal of Finance 61, 2451-2486.

Lee, C.M., Shleifer, A., Thaler, R.H., 1991. Investor sentiment and the closed-end fund puzzle. The Journal of Finance 46, 75-109.

Liu, Y.Y., Nacher, J.C., Ochiai, T., Martino, M., Altshuler, Y., 2014. Prospect theory for online financial trading. PLoS One 9, 1-7.

Lorge, I., Fox, D., Davitz, J., Brenner, M., 1958. A survey of studies contrasting the quality of group performance and individual performance. Psychological Bulletin 55, $337-372$.

Malkiel, B.G., Fama, E.F., 1970. Efficient capital markets: A review of theory and empirical work. The Journal of Finance 25, 383-417. 
Massari, F., 2016. Price probabilities: A class of bayesian and non-bayesian prediction rules. Working paper .

Massari, F., 2017. Markets with heterogeneous beliefs: A necessary and sufficient condition for. Working paper .

Muchnik, L., Aral, S., Taylor, S.J., 2013. Social influence bias: A randomized experiment. Science 341, 647-651.

Oehler, A., Horn, M., Wendt, S., 2016. Benefits from social trading? Empirical evidence for certificates on wikifolios. International Review of Financial Analysis 46, 202-210.

Pan, W., Altschuler, Y., Pentland, A.S., 2012. Decoding social influence and the wisdom of the crowd in financial trading network, in: International Conference on Privacy, Security, Risk and Trust and International Conference on Social Computing, Institute of Electrical and Electronics Engineers. pp. 203-209.

Pedraza, A., Pulga, F., 2019. Asset price effects of peer benchmarking: Evidence from a natural experiment. International Review of Economics \& Finance 62, $53-65$.

Pelster, M., 2017. I'll have what s/he's having: A case study of a social trading network. Proceedings of the International Conference on Information Systems 2017.

Pelster, M., Breitmayer, B., 2019. Attracting attention from peers: Excitement in social trading. Journal of Economic Behavior \& Organization 161, 158 - 179.

Pelster, M., Hofmann, A., 2018. About the fear of reputational loss: Social trading and the disposition effect. Journal of Banking \& Finance 94, 75-88.

Radner, R., 1979. Rational expectations equilibrium: Generic existence and the information revealed by prices. Econometrica 47, 655-678.

Sandroni, A., 2000. Do markets favor agents able to make accurate predictions? Econometrica 68, 1303-1341.

Stein, C., et al., 1956. Inadmissibility of the usual estimator for the mean of a multivariate normal distribution, in: Proceedings of the Third Berkeley symposium on mathematical statistics and probability, pp. 197-206.

Surowiecki, J., 2004. The Wisdom of Crowds. Anchor Books, New York, NY.

Tang, S., Liu, Q., McQueen, M., Counts, S., Jain, A., Zheng, H., Zhao, B.Y., 2017. Echo chambers in investment discussion boards, in: ICWSM (Ed.), The 11th International Conference on Web and Social Media. AAAI Press, Montreal, pp. 240-249.

Tetlock, P., 2007. Giving content to investor sentiment: The role of media in the stock market. The Journal of Finance 62, 1139-1168.

The Securities and Exchange Commission, 2012. Investment adviser use of social media. National Examination Risk Alert.

Tsukioka, Y., Yanagi, J., Takada, T., 2018. Investor sentiment extracted from internet stock message boards and ipo puzzles. International Review of Economics \& Finance $56,205-217$. 
Vasile, D., Sebastian, T.C., Radu, T., 2012. An introduction to behavioral corporate finance. Annals of the University of Oradea, Economic Science Series 21, 471-476.

Vovk, V.G., 1990. Aggregating strategies, in: Proc. Third Workshop on Computational Learning Theory, Morgan Kaufmann. pp. 371-383.

Wang, G., Wang, T., Wang, B., Sambasivan, D., Zhang, Z., 2015. Crowds on wall street: Extracting value from collaborative investing platforms, in: Proceedings of the 18th ACM Conference on Computer Supported Cooperative Work \& Social Computing, ACM. pp. 17-30.

Yaniv, I., Milyavsky, M., 2007. Using advice from multiple sources to revise and improve judgments. Organizational Behavior and Human Decision Processes 103, 104-120. 


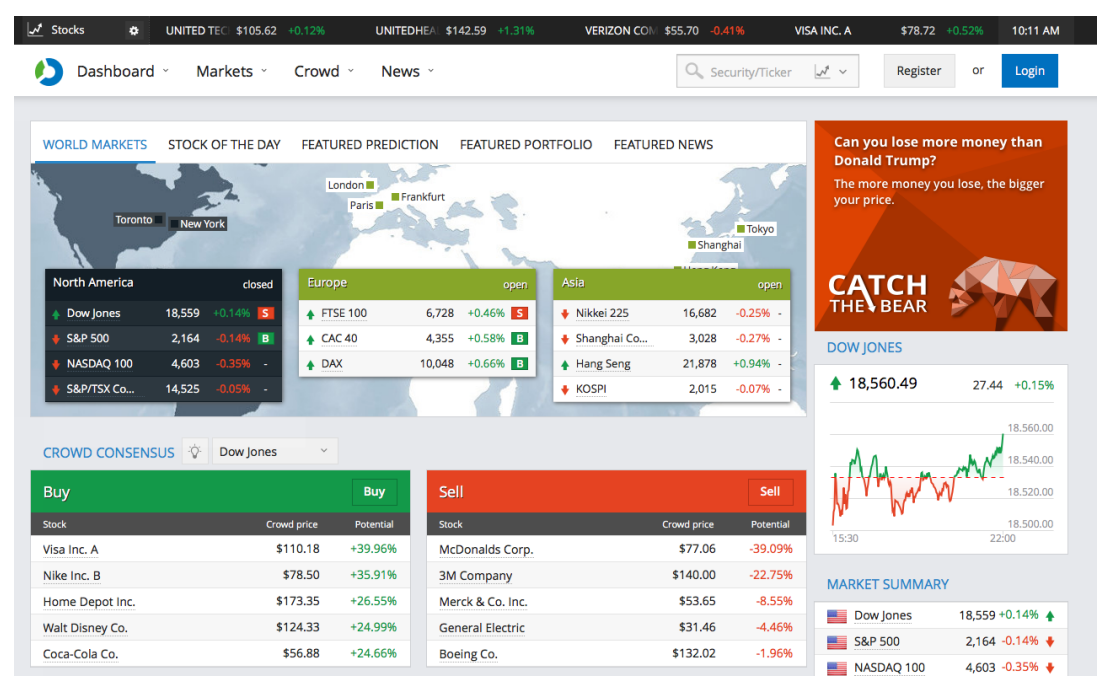

Figure 1: Welcome page of Sharewise online trading platform (upper part)

The figure depicts the upper part of the welcome page of the online trading platform Sharewise. The page presents current information on the major price indexes around the world and on the crowd consensus for the five stocks with the highest and lowest Potential, as predicted by the platform's community.

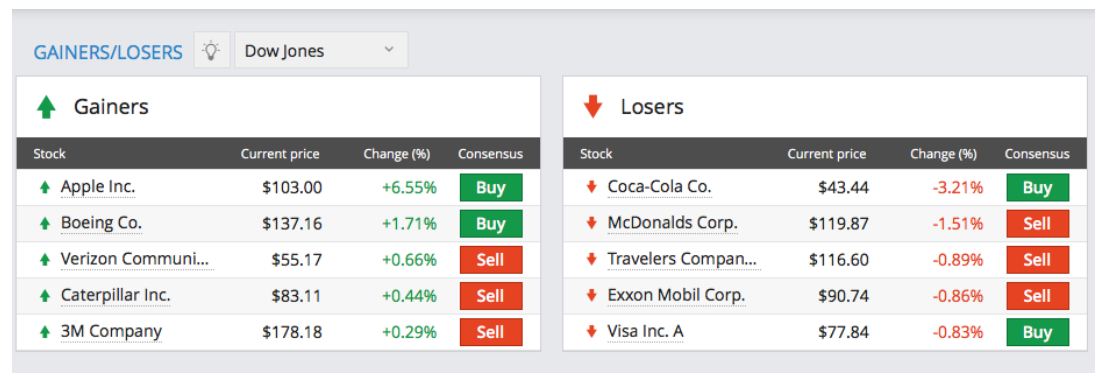

Figure 2: Welcome page of Sharewise online trading platform (middle part)

The figure depicts the middle part of the welcome page of the online trading platform Sharewise. The page presents information on the five stocks with the highest and lowest returns over the current trading day. 


\begin{tabular}{|c|c|c|c|c|}
\hline UPDATES & All & & & \\
\hline Date & Stock & Type & Category & Target price \\
\hline a day ago & Illumina Inc. & \& Buy & Crowd consensus & $\$ 185.17$ \\
\hline a day ago & Alstom S.A. Inh. & $\downarrow$ Sell & Crowd consensus & $\$ 24.94$ \\
\hline a day ago & Henkel AG \& Co. KGaA VZO & 4 Buy & Crowd consensus & $\$ 115.31$ \\
\hline a day ago & Air France-KLM S.A. & 4 Buy & Crowd consensus & $\$ 8.332$ \\
\hline a day ago & Nemetschek AG & + Sell & Crowd consensus & $\$ 58.35$ \\
\hline a day ago & Chipmos Technologies & + Sell & Crowd consensus & $\$ 18.00$ \\
\hline a day ago & Vinci S.A. Inh. & $\checkmark$ Sell & Crowd consensus & $\$ 75.46$ \\
\hline a day ago & Yahoo Inc. & $\downarrow$ Sell & Crowd consensus & $\$ 37.61$ \\
\hline a day ago & Chemocentryx Inc. & + Sell & Crowd consensus & $\$ 4.500$ \\
\hline a day ago & Vericel Corp. & 4 Buy & Crowd consensus & $\$ 2.875$ \\
\hline
\end{tabular}

Figure 3: Welcome page of Sharewise online trading platform (lower part)

The figure depicts the lower part of the welcome page of the online trading platform Sharewise. The lower part presents information on the latest updates of the crowd consensus.

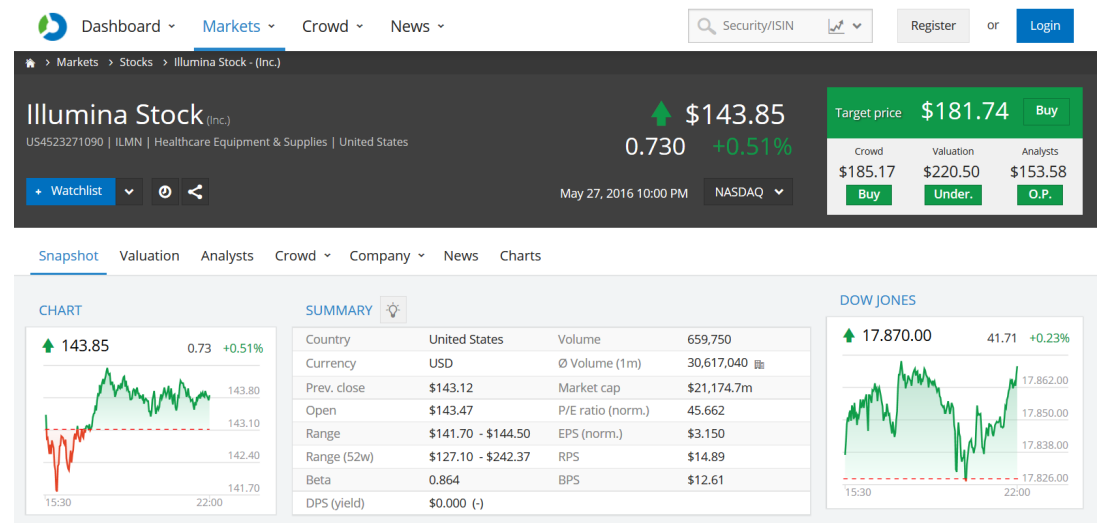

Figure 4: Instrument page of Sharewise online trading platform (upper part)

The figure depicts a screenshot of the upper part of the instrument page of a selected instrument (Example: Illumina Stock). 


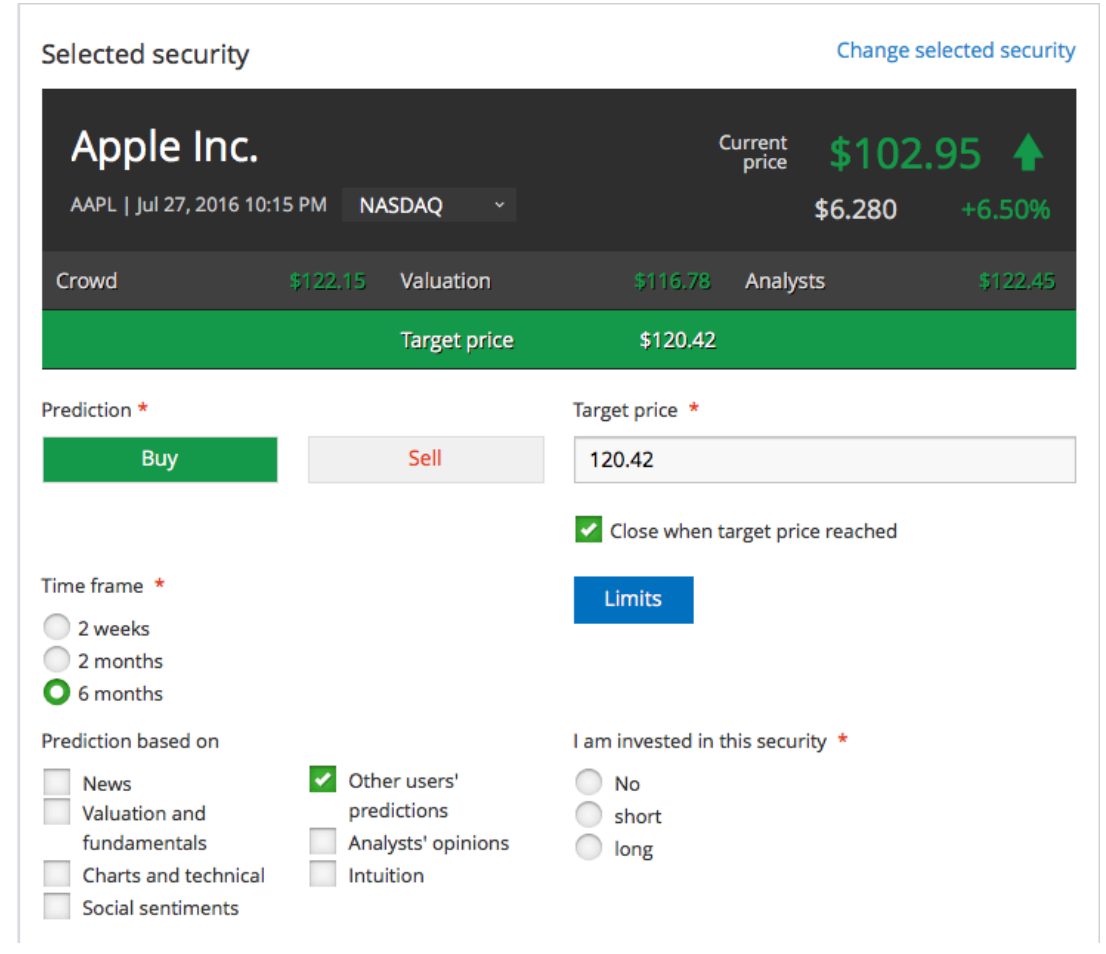

Figure 5: User front end of Sharewise online trading platform

The figure depicts the user front end of the online trading platform Sharewise for the stock of Apple Inc. The right-hand side shows the current stock value and the most recent change in the stock price. Below, the front end shows the assessment of the crowd, the fundamental value of the stock, and the assessment of professional stock analysts. Next, the front end shows a cumulated target price calculated by Sharewise. Below this information, users can provide their own contribution to the crowd assessment. Users can voice buy or sell recommendations and specify a target price. They can provide information on the basis for their assessment and whether they are invested in the stock through a long or short position. 
3M Company

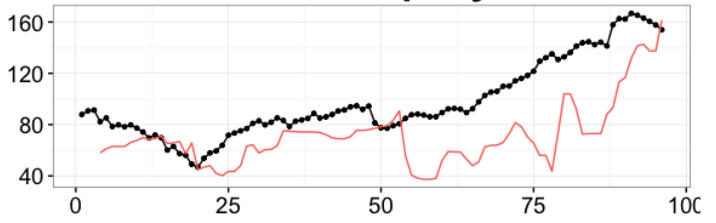

Exxon Mobile

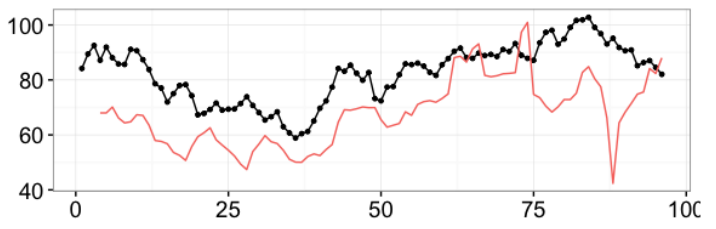

J.P. Morgan Chase

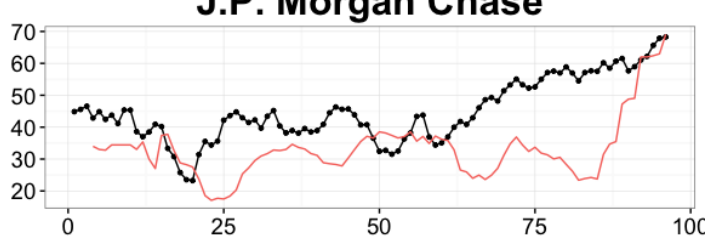

Apple

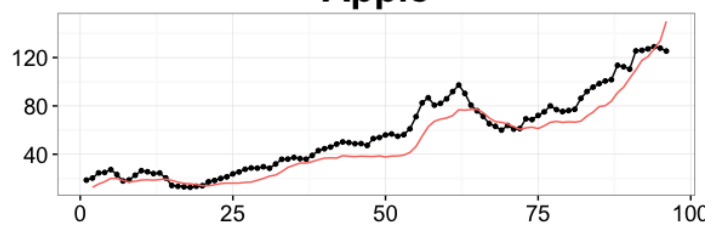

Figure 6: Evolution of stock prices and crowd consensus for selected stocks.

The figure presents the evolution of stock prices (black) and the crowd consensus (red) of the Sharewise social investment platform for selected stocks over our sample period from 2007 to 2015 . The upper-left panel shows the evolution of stock of 3M Company, the top-right panel reports on J.P Morgan Chase, the lower-left panel on Exxon Mobile, and the lower-right panel shows the evolution of Apple stock and the crowd consensus.

\begin{tabular}{cccrcc}
\hline Date & ISIN & Instrument ID & Buy & Sell & Average Expected Price \\
\hline 28.01 .2011 & DE0005140008 & 1,650 & 119 & 11 & 49.721 \\
28.01 .2011 & NL0000235190 & 2,164 & 23 & 11 & 20.97 \\
28.01 .2011 & FR0000120628 & 3,861 & 57 & 16 & 15.391 \\
28.01 .2011 & US0378331005 & 4,335 & 28 & 14 & 38.204 \\
31.01 .2011 & DE0005190003 & 1,555 & 26 & 11 & 56.986 \\
31.01 .2011 & DE0005140008 & 1,650 & 120 & 12 & 49.689 \\
31.01 .2011 & FR0000120628 & 3,861 & 57 & 17 & 15.419 \\
31.01 .2011 & US0378331005 & 4,335 & 29 & 14 & 38.23 \\
\hline
\end{tabular}

Table 1: Example excerpt of Sharewise dataset

The table provides an example excerpt of the Sharewise dataset. The data contain the date, the ISIN of the underlying, a unique Sharewise identifier, the total number of buy and sell recommendations and the average expected price (crowd consensus). 


\begin{tabular}{l|rrrrrrrr}
\hline & $\mathrm{N}$ & Mean & SD & Skewness & Kurtosis & Median & Min & Max \\
\hline Total opinion & 73,015 & 170.404 & 363.220 & 8.617 & 144.125 & 66 & 1 & 13315 \\
Total buy & 73,015 & 140.449 & 313.514 & 9.203 & 169.730 & 63 & 0 & 12492 \\
Total sell & 73,015 & 29.955 & 83.882 & 10.599 & 263.054 & 0 & 0 & 4658 \\
Potential & 73,015 & -0.048 & 0.586 & 0.877 & 5.395 & -0.062 & -0.996 & 2.275 \\
Potential (buy consensus) & 32,467 & 0.423 & 0.476 & 2.198 & 8.021 & 0.263 & 0.000 & 2.275 \\
Potential (sell consensus) & 40,548 & -0.425 & 0.343 & -0.590 & 1.802 & -0.286 & -0.996 & 0.000 \\
\hline 6M buy-hold & 73,015 & 0.052 & 0.333 & 1.060 & 6.118 & 0.024 & -0.679 & 1.420 \\
Abnormal return & 73,015 & 0.050 & 0.331 & 1.069 & 6.112 & 0.023 & -0.669 & 1.412 \\
Stock volatility & 68,613 & 0.027 & 0.015 & 1.422 & 5.423 & 0.024 & 0.002 & 0.083 \\
Illiquidity & 61,660 & -0.001 & 0.002 & -5.956 & 40.233 & 0.000 & -0.018 & 0.000 \\
Stock market return & 73,015 & 0.000 & 0.001 & -1.074 & 5.065 & 0.000 & -0.008 & 0.007 \\
\hline Market value of equity & 72,759 & 182 & 3,913 & 46.540 & 2563.793 & 2 & 0 & 290,000 \\
Market value of equity $(\log )$ & 72,759 & 7.409 & 2.778 & 0.255 & 2.934 & 7.392 & 0.000 & 19.484 \\
Total assets & 63,508 & 173,000 & 799,000 & 6.693 & 50.699 & 2 & 6 & $6,640,000$ \\
Total assets (log) & 63,508 & 14.789 & 3.038 & 0.306 & 2.681 & 14.645 & 8.652 & 22.617 \\
Book-to-market & 63,426 & 0.696 & 0.683 & 2.448 & 11.864 & 0.539 & -0.383 & 4.303 \\
\hline Earnings surprises & 41,331 & -1.395 & 132.748 & -1.322 & 19.596 & 2.929 & -758.871 & 600.000 \\
Analyst opinion & 62,702 & -0.010 & 0.237 & -0.047 & 16.789 & -0.007 & -0.984 & 1.227 \\
News sentiment & 10,993 & 0.158 & 0.255 & -0.256 & 6.223 & 0.164 & -1.000 & 1.000 \\
Google search volume & 63,153 & 36.742 & 23.966 & 0.304 & 2.008 & 35.300 & 0.000 & 97.383 \\
\hline
\end{tabular}

Table 2: Summary statistics: Sharewise data and dependent variables

The table reports summary statistics for the main variables of interest for our dataset. We report summary statistics for Sharewise data and dependent variables. Data on crowd stock opinions are from Sharewise. Stock price data and fundamentals are from Thomson Reuters Datastream and Worldscope. In total, our sample runs from August 1, 2007, to July 15, 2015, and contains 73,015 stock-quarter observations. Detailed data definitions and data sources can be found in Table A.1. Market value of equity and Total assets are given in thousands of USD. 


\begin{tabular}{|c|c|c|c|c|c|c|c|c|c|c|c|c|c|}
\hline Variables & Total buy & Total sell & Potential & $6 \mathrm{M}$ buy-hold & Abnormal return & Analyst opinion & Earnings surprises & News sentiment & Google search volume & Stock market return & Total assets & Book to-market & Stock volat ility \\
\hline Total sell & \begin{tabular}{|l|}
$\begin{array}{l}0.506 \\
(0.000)\end{array}$ \\
\end{tabular} & & & & & & & & & & & & \\
\hline Potential & $\left.\begin{array}{|l|l}0.166 \\
(0.000)\end{array}\right]$ & $\begin{array}{l}-0.033 \\
(0.000)\end{array}$ & & & & & & & & & & & \\
\hline $6 \mathrm{M}$ buy-hold & $\begin{array}{l}-0.033 \\
(0.000)\end{array}$ & $\begin{array}{l}-0.001 \\
(0.726)\end{array}$ & $\begin{array}{c}0.025 \\
(0.000)\end{array}$ & & & & & & & & & & \\
\hline Abnormal returm & $\begin{array}{l}-0.031 \\
(0.000)\end{array}$ & $\begin{array}{l}0.000 \\
(0.972)\end{array}$ & $\begin{array}{c}0.022 \\
(0.000)\end{array}$ & $\begin{array}{l}0.998 \\
(0.000)\end{array}$ & & & & & & & & & \\
\hline Analyst opinion & $\begin{array}{l}0.021 \\
(0.000)\end{array}$ & $\begin{array}{l}0.025 \\
(0.000)\end{array}$ & $\begin{array}{l}0.296 \\
(0.000)\end{array}$ & $\begin{array}{l}-0.176 \\
(0.0000)\end{array}$ & $\begin{array}{l}-0.174 \\
(0.0000)\end{array}$ & & & & & & & & \\
\hline Earnings surprises & \begin{tabular}{|l|l|}
-0.007 \\
$(0.179)$
\end{tabular} & $\begin{array}{l}0.010 \\
(0.033)\end{array}$ & $\begin{array}{l}-0.025 \\
(0.0000)\end{array}$ & $\begin{array}{l}0.060 \\
(0.000)\end{array}$ & $\begin{array}{l}0.059 \\
(0.000)\end{array}$ & $\begin{array}{l}-0.009 \\
(0.073)\end{array}$ & & & & & & & \\
\hline News sentiment & 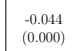 & $\begin{array}{l}-0.068 \\
(0.000)\end{array}$ & $\begin{array}{c}0.002 \\
(0.817)\end{array}$ & $\begin{array}{l}0.085 \\
(0.000)\end{array}$ & $\begin{array}{l}0.086 \\
(0.000)\end{array}$ & $\begin{array}{l}-0.038 \\
(0.0000)\end{array}$ & $\begin{array}{l}0.019 \\
(0.053)\end{array}$ & & & & & & \\
\hline Google search volume & $\begin{array}{c}0.046 \\
(0.000)\end{array}$ & $\begin{array}{c}0.042 \\
(0.000)\end{array}$ & $\begin{array}{l}-0.037 \\
(0.0000)\end{array}$ & $\begin{array}{l}0.011 \\
(0.008)\end{array}$ & $\begin{array}{l}0.010 \\
(0.008)\end{array}$ & $\begin{array}{l}-0.0099 \\
(0.038)\end{array}$ & $\begin{array}{r}-0.005 \\
(0.381)\end{array}$ & $\begin{array}{c}-0.024 \\
(0.014)\end{array}$ & & & & & \\
\hline Stock market return & $\begin{array}{c}-0.014 \\
(0.000)\end{array}$ & $\begin{array}{l}0.010 \\
(0.008)\end{array}$ & $\begin{array}{l}0.009 \\
(0.016)\end{array}$ & $\begin{array}{c}0.324 \\
(0.000)\end{array}$ & $\begin{array}{c}0.320 \\
(0.000)\end{array}$ & $\begin{array}{l}-0.129 \\
(0.000)\end{array}$ & $\begin{array}{l}0.021 \\
(0.000)\end{array}$ & $\begin{aligned}-0.014 \\
(0.131)\end{aligned}$ & $\begin{array}{l}-0.015 \\
(0.000)\end{array}$ & & & & \\
\hline Total assets & $\begin{array}{c}0.008 \\
(0.046)\end{array}$ & $\begin{array}{l}0.039 \\
(0.000)\end{array}$ & $\begin{array}{c}-0.276 \\
(0.0000)\end{array}$ & $\begin{array}{l}-0.004 \\
(0.283)\end{array}$ & $\begin{array}{l}-0.0033 \\
(0.502)\end{array}$ & $\begin{array}{l}-0.037 \\
(0.0000)\end{array}$ & $\begin{array}{l}0.016 \\
(0.003)\end{array}$ & $\begin{array}{l}-0.0600 \\
(0.0000)\end{array}$ & $\begin{array}{l}0.009 \\
(0.043)\end{array}$ & $\begin{array}{l}0.008 \\
(0.036)\end{array}$ & & & \\
\hline Book-to-market & $\begin{array}{c}0.060 \\
(0.000)\end{array}$ & $\begin{array}{c}0.011 \\
(0.006)\end{array}$ & $\begin{array}{c}0.212 \\
(0.000)\end{array}$ & $\begin{array}{c}-0.121 \\
(0.0000)\end{array}$ & $\begin{array}{l}-0.121 \\
(0.0000)\end{array}$ & $\begin{array}{l}0.187 \\
(0.000)\end{array}$ & $\begin{array}{l}-0.032 \\
(0.0000)\end{array}$ & $\begin{array}{r}-0.026 \\
(0.010)\end{array}$ & $\begin{array}{c}0.025 \\
(0.000)\end{array}$ & $\begin{array}{r}-0.031 \\
(0.0000)\end{array}$ & $\begin{array}{c}0.079 \\
(0.0000)\end{array}$ & & \\
\hline Stock volatility & $\begin{array}{c}0.014 \\
(0.000)\end{array}$ & $\begin{array}{l}-0.057 \\
(0.000)\end{array}$ & $\begin{array}{c}0.220 \\
(0.000)\end{array}$ & $\begin{array}{l}-0.119 \\
(0.0000)\end{array}$ & $\begin{array}{l}-0.117 \\
(0.0000)\end{array}$ & $\begin{array}{c}0.038 \\
(0.000)\end{array}$ & $\begin{array}{l}-0.063 \\
(0.000)\end{array}$ & $\begin{array}{l}-0.023 \\
(0.019)\end{array}$ & $\begin{array}{l}-0.117 \\
(0.000)\end{array}$ & $\begin{array}{l}-0.131 \\
(0.000)\end{array}$ & $\begin{array}{c}-0.084 \\
(0.0000)\end{array}$ & $\begin{array}{c}0.071 \\
(0.000)\end{array}$ & \\
\hline Illiquidity & $\begin{array}{l}0.025 \\
0.0000\end{array}$ & $\begin{array}{l}0.051 \\
(0.000)\end{array}$ & $\begin{array}{l}-0.197 \\
0.000)\end{array}$ & $\begin{array}{l}0.057 \\
(0.000)\end{array}$ & $\begin{array}{l}0.062 \\
0.0000\end{array}$ & $\begin{array}{l}-0.039 \\
0.000\end{array}$ & $\begin{array}{l}0.025 \\
0.0000\end{array}$ & $\begin{array}{l}-0.011 \\
(0.266)\end{array}$ & $\begin{array}{l}0.044 \\
(0.000)\end{array}$ & $\begin{array}{l}0.042 \\
0.0001\end{array}$ & $\begin{array}{r}0.050 \\
0.0000\end{array}$ & $\begin{array}{l}-0.100 \\
(0.000)\end{array}$ & $\begin{array}{l}-0.193 \\
0.0003\end{array}$ \\
\hline
\end{tabular}

Table 3: Correlations between selected variables

The table reports the pairwise correlations between selected variables (upper value). $p$-values are shown in parenthesis. Data on crowd stock opinions are from Sharewise. Stock price data and fundamentals are from Thomson Reuters Datastream and Worldscope, Google search volume data are from Google trends, and News sentiment data are from Quandl. In total, our sample runs from August 1, 2007, to July 15, 2015, and contains 73,015 stock-quarter observations. Detailed data definitions and data sources can be found in Table A.1. 


\begin{tabular}{|c|c|c|c|c|c|c|c|c|}
\hline & Model (1) & Model (2) & $\overline{~ M o d e l ~(3) ~}$ & Model (4) & Model (5) & Model (6) & Model (7) & "Model (8) \\
\hline \multirow[t]{2}{*}{ Alpha } & 0.0331 & 0.0321 & 0.0332 & 0.0321 & 0.0321 & 0.0321 & 0.0326 & 0.0331 \\
\hline & $(0.0026)$ & $(0.0027)$ & $(0.0026)$ & $(0.0028)$ & $(0.0027)$ & $(0.0027)$ & $(0.0035)$ & $(0.0028)$ \\
\hline \multirow[t]{2}{*}{ Mkt-RF } & -0.0000 & 0.0002 & -0.0002 & 0.0002 & 0.0002 & 0.0001 & 0.0002 & 0.0002 \\
\hline & $(0.0003)$ & $(0.0004)$ & $(0.0004)$ & $(0.0004)$ & $(0.0004)$ & $(0.0004)$ & $(0.0004)$ & $(0.0004)$ \\
\hline \multirow[t]{2}{*}{ HML } & & 0.0004 & 0.0005 & 0.0007 & 0.0004 & 0.0000 & 0.0004 & 0.0002 \\
\hline & & $(0.0007)$ & $(0.0006)$ & $(0.0007)$ & $(0.0007)$ & $(0.0007)$ & $(0.0007)$ & $(0.0007)$ \\
\hline \multirow[t]{2}{*}{ SMB } & & 0.0011 & 0.0007 & 0.0011 & 0.0011 & 0.0010 & 0.0011 & 0.0012 \\
\hline & & $(0.0008)$ & $(0.0007)$ & $(0.0008)$ & $(0.0008)$ & $(0.0008)$ & $(0.0008)$ & $(0.0008)$ \\
\hline \multirow[t]{2}{*}{ RMW } & & 0.0028 & & 0.0028 & 0.0028 & 0.0031 & 0.0028 & 0.0027 \\
\hline & & $(0.0015)$ & & $(0.0015)$ & $(0.0016)$ & $(0.0015)$ & $(0.0016)$ & $(0.0015)$ \\
\hline \multirow[t]{2}{*}{ CMA } & & -0.0001 & & -0.0003 & -0.0001 & -0.0005 & 0.0000 & 0.0004 \\
\hline & & $(0.0016)$ & & $(0.0015)$ & $(0.0015)$ & $(0.0018)$ & $(0.0016)$ & $(0.0017)$ \\
\hline Mom & & & $\begin{array}{c}0.0002 \\
(0.0003)\end{array}$ & $\begin{array}{c}0.0002 \\
(0.0003)\end{array}$ & & & & \\
\hline STrev & & & & & $\begin{array}{l}0.0000 \\
(0.0005)\end{array}$ & & & \\
\hline LTrev & & & & & & $\begin{array}{c}0.0009 \\
(0.0008)\end{array}$ & & \\
\hline SENT & & & & & & & $\begin{array}{c}0.0021 \\
(0.0074)\end{array}$ & \\
\hline OSENT & & & & & & & & $\begin{array}{c}0.0083 \\
(0.0076)\end{array}$ \\
\hline Observations & 96 & 96 & 96 & 96 & 96 & 96 & 96 & 96 \\
\hline
\end{tabular}

Table 4: Price performance of Potential stocks

The table reports coefficients obtained from the time-series regressions on returns of a portfolio that is long stocks with the largest potential (upper third) and short stocks with the lowest potential (lower third) as indicated by the Sharewise crowd on a host of well-known factors. Each regression is estimated with monthly aggregated data over the 96-month sample period from August 2007 to July 2015. Mkt$\mathrm{RF}$ is the excess monthly market return. SMB is the return of a portfolio long small stocks and short large stocks. HML is the return of a portfolio long high book-to-market stocks and short low book-tomarket stocks. RMW is the return of a portfolio long high operating profitability stocks and short low operating profitability stocks. CMA is the return of a portfolio long high investment stocks and short low investment stocks. MOM denotes the momentum factor proposed by Carhart (1997). STrev and LTrev denote returns of portfolios created on short-term and long-term reversal, respectively. SENT and OSENT denote returns of portfolios based on investor sentiment and on sentiment proxies orthogonalized with respect to macroeconomic indicators (Baker and Wurgler, 2006), respectively. Standard errors (reported in parentheses) are adjusted for serial correlation using the Newey-West correction. Data on crowd stock opinions are from Sharewise. Returns of traditional factors are obtained from Kenneth French official website. 


\begin{tabular}{|c|c|c|c|c|c|c|}
\hline & Model (1) & Model (2) & Model (3) & Model (4) & Model (5) & Model (6) \\
\hline & Full sample & Full sample + Controls & Low Consensus & High Consensus & High Potential vola & High Sell Potential \\
\hline Potential & $\begin{array}{c}0.092 \\
(14.38)\end{array}$ & $\begin{array}{c}0.096 \\
(11.20)\end{array}$ & $\begin{array}{l}0.116 \\
(3.68)\end{array}$ & $\begin{array}{l}0.107 \\
(6.64)\end{array}$ & $\begin{array}{l}0.075 \\
(7.20)\end{array}$ & $\begin{array}{l}0.138 \\
(5.96)\end{array}$ \\
\hline Analyst opinion & & $\begin{array}{l}0.243 \\
(9.07)\end{array}$ & $\begin{array}{l}0.343 \\
(4.74)\end{array}$ & $\begin{array}{l}0.272 \\
(4.37)\end{array}$ & $\begin{array}{l}0.223 \\
(6.54)\end{array}$ & $\begin{array}{l}0.446 \\
(5.61)\end{array}$ \\
\hline Stock market return & & $\begin{array}{c}49.81 \\
(18.94)\end{array}$ & $\begin{array}{l}47.22 \\
(3.61)\end{array}$ & $\begin{array}{l}32.54 \\
(6.01)\end{array}$ & $\begin{array}{c}53.71 \\
(14.84)\end{array}$ & $\begin{array}{l}60.35 \\
(8.12)\end{array}$ \\
\hline Google search volume & & $\begin{array}{l}0.001 \\
(2.22)\end{array}$ & $\begin{array}{l}0.002 \\
(1.71)\end{array}$ & $\begin{array}{l}0.001 \\
(1.76)\end{array}$ & $\begin{array}{l}0.001 \\
(2.00)\end{array}$ & $\begin{array}{l}0.001 \\
(1.49)\end{array}$ \\
\hline Illiquidity & & $\begin{array}{l}12.81 \\
(6.58)\end{array}$ & $\begin{array}{l}24.65 \\
(2.04)\end{array}$ & $\begin{array}{l}11.48 \\
(4.83)\end{array}$ & $\begin{array}{l}10.22 \\
(3.81)\end{array}$ & $\begin{array}{l}-1.857 \\
(-0.10)\end{array}$ \\
\hline Size & & $\begin{array}{l}-0.000 \\
(-0.02)\end{array}$ & $\begin{array}{l}0.024 \\
(0.63)\end{array}$ & $\begin{array}{l}0.020 \\
(1.02)\end{array}$ & $\begin{array}{c}0.024 \\
(1.66)\end{array}$ & $\begin{array}{l}-0.006 \\
(-0.18)\end{array}$ \\
\hline Book-to-market & & $\begin{array}{l}-0.155 \\
(-17.93)\end{array}$ & $\begin{array}{l}-0.102 \\
(-3.28)\end{array}$ & $\begin{array}{l}-0.136 \\
(-8.20)\end{array}$ & $\begin{array}{c}-0.151 \\
(-14.15)\end{array}$ & $\begin{array}{l}-0.171 \\
(-5.17)\end{array}$ \\
\hline Dividend yield & & $\begin{array}{c}-0.026 \\
(-18.10)\end{array}$ & $\begin{array}{l}-0.021 \\
(-3.65)\end{array}$ & $\begin{array}{l}-0.020 \\
(-8.13)\end{array}$ & $\begin{array}{c}-0.025 \\
(-13.55)\end{array}$ & $\begin{array}{l}-0.033 \\
(-6.94)\end{array}$ \\
\hline Constant & $\begin{array}{c}-0.173 \\
(-11.00)\end{array}$ & $\begin{array}{l}0.011 \\
(0.07)\end{array}$ & $\begin{array}{l}-0.421 \\
(-0.75)\end{array}$ & $\begin{array}{l}-0.402 \\
(-1.44)\end{array}$ & $\begin{array}{l}-0.424 \\
(-1.98)\end{array}$ & $\begin{array}{l}0.189 \\
(0.32)\end{array}$ \\
\hline $\begin{array}{l}\text { Stock fixed effects } \\
\text { Time fixed effects }\end{array}$ & $\begin{array}{l}\text { Yes } \\
\text { Yes }\end{array}$ & $\begin{array}{l}\text { Yes } \\
\text { Yes }\end{array}$ & $\begin{array}{l}\text { Yes } \\
\text { Yes }\end{array}$ & $\begin{array}{l}\text { Yes } \\
\text { Yes }\end{array}$ & $\begin{array}{l}\text { Yes } \\
\text { Yes }\end{array}$ & $\begin{array}{l}\text { Yes } \\
\text { Yes }\end{array}$ \\
\hline $\begin{array}{l}\text { Observations } \\
\mathrm{R}^{2} \\
\text { Adj. } \mathrm{R}^{2} \\
\mathrm{~F}\end{array}$ & $\begin{array}{c}73,015 \\
0.24 \\
0.24 \\
293.00 \\
\end{array}$ & $\begin{array}{c}44,944 \\
0.34 \\
0.33 \\
268.00 \\
\end{array}$ & $\begin{array}{c}1,564 \\
0.46 \\
0.45 \\
17.61 \\
\end{array}$ & $\begin{array}{c}9,023 \\
0.35 \\
0.35 \\
62.24 \\
\end{array}$ & $\begin{array}{c}26,156 \\
0.37 \\
0.37 \\
190.40 \\
\end{array}$ & $\begin{array}{c}7,622 \\
0.29 \\
0.29 \\
27.76 \\
\end{array}$ \\
\hline
\end{tabular}

Table 5: Sharewise stock opinions and six-month buy-and-hold returns (Panel A)

The table reports the results of our panel regressions with stock and time fixed effects using six month buy-and-hold return as dependent variable. Stock opinions are lagged by six months. We use robust standard errors clustered at the individual stock level to mitigate possible issues due to heteroskedasticity and serial correlation. $t$-statistics are in parentheses. Data on crowd stock opinions are from Sharewise. Stock price data and fundamentals are from Thomson Reuters Datastream and Worldscope, and Google search volume data are from Google trends. In total, our sample runs from August 1, 2007, to July 15, 2015, and contains 73,015 stock-quarter observations. Detailed data definitions and data sources can be found in Table A.1 


\begin{tabular}{|c|c|c|c|c|c|c|c|c|c|}
\hline & Model (1) & Model (2) & Model (3) & Model (4) & Model (5) & Model (6) & Model (7) & Model (8) & Model (9) \\
\hline & Hard to Value & Easy to Value & Loser Stocks & Low Attention & High Attention & Few Opinions & Many Opinions & Earnings surprises & News Sentiment \\
\hline Potential & $\begin{array}{l}0.129 \\
(7.73)\end{array}$ & $\begin{array}{l}0.026 \\
(2.93)\end{array}$ & $\begin{array}{l}0.099 \\
(8.60)\end{array}$ & $\begin{array}{l}0.126 \\
(7.61)\end{array}$ & $\begin{array}{l}0.183 \\
(9.52)\end{array}$ & $\begin{array}{l}0.079 \\
(6.91)\end{array}$ & $\begin{array}{l}0.146 \\
(6.06)\end{array}$ & $\begin{array}{l}0.115 \\
(9.51)\end{array}$ & $\begin{array}{l}0.161 \\
(6.54)\end{array}$ \\
\hline Analyst opinion & $\begin{array}{l}0.307 \\
(7.42)\end{array}$ & $\begin{array}{l}0.208 \\
(4.29)\end{array}$ & $\begin{array}{l}0.259 \\
(7.89)\end{array}$ & $\begin{array}{l}0.398 \\
(6.97)\end{array}$ & $\begin{array}{l}0.368 \\
(7.22)\end{array}$ & $\begin{array}{l}0.373 \\
(9.08)\end{array}$ & $\begin{array}{l}0.181 \\
(3.38)\end{array}$ & $\begin{array}{l}0.220 \\
(5.85)\end{array}$ & $\begin{array}{l}0.442 \\
(4.65)\end{array}$ \\
\hline Stock market return & $\begin{array}{l}54.19 \\
(8.51)\end{array}$ & $\begin{array}{c}36.01 \\
(13.16)\end{array}$ & $\begin{array}{c}52.83 \\
(13.15)\end{array}$ & $\begin{array}{l}43.62 \\
(8.60)\end{array}$ & $\begin{array}{l}45.87 \\
(8.07)\end{array}$ & $\begin{array}{l}47.08 \\
(10.47)\end{array}$ & $\begin{array}{l}56.95 \\
(10.35)\end{array}$ & $\begin{array}{c}57.06 \\
(13.46)\end{array}$ & $\begin{array}{l}72.69 \\
(3.61)\end{array}$ \\
\hline Google search volume & $\begin{array}{l}0.001 \\
(1.50)\end{array}$ & $\begin{array}{l}0.000 \\
(1.22)\end{array}$ & $\begin{array}{l}0.001 \\
(1.61)\end{array}$ & $\begin{array}{l}-0.000 \\
(-0.04)\end{array}$ & $\begin{array}{l}0.001 \\
(0.62)\end{array}$ & $\begin{array}{l}0.001 \\
(1.45)\end{array}$ & $\begin{array}{l}-0.000 \\
(-0.62)\end{array}$ & $\begin{array}{l}0.000 \\
(0.96)\end{array}$ & $\begin{array}{l}0.003 \\
(2.49)\end{array}$ \\
\hline Illiquidity & $\begin{array}{l}12.50 \\
(3.46)\end{array}$ & $\begin{array}{c}8.12 \\
(0.75)\end{array}$ & $\begin{array}{l}12.70 \\
(3.72)\end{array}$ & $\begin{array}{l}12.45 \\
(2.91)\end{array}$ & $\begin{array}{l}10.07 \\
(1.43)\end{array}$ & $\begin{array}{l}10.33 \\
(2.82)\end{array}$ & $\begin{array}{l}16.04 \\
(2.60)\end{array}$ & $\begin{array}{c}9.25 \\
(1.69)\end{array}$ & $\begin{array}{l}68.60 \\
(0.90)\end{array}$ \\
\hline Size & $\begin{array}{l}0.030 \\
(1.52)\end{array}$ & $\begin{array}{l}-0.016 \\
(-1.40)\end{array}$ & $\begin{array}{l}0.003 \\
(0.21)\end{array}$ & $\begin{array}{l}0.014 \\
(0.59)\end{array}$ & $\begin{array}{l}0.044 \\
(1.64)\end{array}$ & $\begin{array}{l}0.025 \\
(1.50)\end{array}$ & $\begin{array}{l}-0.030 \\
(-1.18)\end{array}$ & $\begin{array}{l}-0.006 \\
(-0.36)\end{array}$ & $\begin{array}{l}0.015 \\
(0.27)\end{array}$ \\
\hline Book-to-market & $\begin{array}{c}-0.179 \\
(-11.40)\end{array}$ & $\begin{array}{l}-0.110 \\
(-5.63)\end{array}$ & $\begin{array}{c}-0.147 \\
(-14.13)\end{array}$ & $\begin{array}{c}-0.202 \\
(-11.66)\end{array}$ & $\begin{array}{c}-0.218 \\
(-12.00)\end{array}$ & $\begin{array}{c}-0.160 \\
(-10.78)\end{array}$ & $\begin{array}{c}-0.170 \\
(-10.72)\end{array}$ & $\begin{array}{c}-0.157 \\
(-11.28)\end{array}$ & $\begin{array}{l}-0.210 \\
(-3.96)\end{array}$ \\
\hline Dividend yield & $\begin{array}{l}-0.033 \\
(-9.50)\end{array}$ & $\begin{array}{l}-0.024 \\
(-9.15)\end{array}$ & $\begin{array}{c}-0.026 \\
(-14.01)\end{array}$ & $\begin{array}{l}-0.026 \\
(-7.75)\end{array}$ & $\begin{array}{l}-0.024 \\
(-7.36)\end{array}$ & $\begin{array}{l}-0.023 \\
(-9.09)\end{array}$ & $\begin{array}{l}-0.027 \\
(-9.40)\end{array}$ & $\begin{array}{c}-0.028 \\
(-12.83)\end{array}$ & $\begin{array}{l}-0.043 \\
(-4.94)\end{array}$ \\
\hline Earnings surprises & & & & & & & & $\begin{array}{l}0.000 \\
(1.36)\end{array}$ & \\
\hline News sentiment & & & & & & & & & $\begin{array}{l}-0.039 \\
(-1.80)\end{array}$ \\
\hline Constant & $\begin{array}{l}-0.504 \\
(-1.86)\end{array}$ & $\begin{array}{l}0.326 \\
(1.66)\end{array}$ & $\begin{array}{c}-0.0339 \\
(-0.16)\end{array}$ & $\begin{array}{l}-0.244 \\
(-0.70)\end{array}$ & $\begin{array}{l}-0.613 \\
(-1.52)\end{array}$ & $\begin{array}{l}-0.485 \\
(-1.81)\end{array}$ & $\begin{array}{l}0.533 \\
(1.36)\end{array}$ & $\begin{array}{l}0.143 \\
(0.59)\end{array}$ & $\begin{array}{l}-0.174 \\
(-0.20)\end{array}$ \\
\hline $\begin{array}{l}\text { Stock fixed effects } \\
\text { Time fixed effects }\end{array}$ & $\begin{array}{l}\text { Yes } \\
\text { Yes }\end{array}$ & $\begin{array}{l}\text { Yes } \\
\text { Yes }\end{array}$ & $\begin{array}{l}\text { Yes } \\
\text { Yes }\end{array}$ & $\begin{array}{l}\text { Yes } \\
\text { Yes }\end{array}$ & $\begin{array}{l}\text { Yes } \\
\text { Yes }\end{array}$ & $\begin{array}{l}\text { Yes } \\
\text { Yes }\end{array}$ & $\begin{array}{l}\text { Yes } \\
\text { Yes }\end{array}$ & $\begin{array}{l}\text { Yes } \\
\text { Yes }\end{array}$ & $\begin{array}{l}\text { Yes } \\
\text { Yes } \\
\end{array}$ \\
\hline $\begin{array}{l}\text { Observations } \\
\mathrm{R}^{2} \\
\text { Adj. } \mathrm{R}^{2} \\
\mathrm{~F} \\
\end{array}$ & $\begin{array}{c}11,664 \\
0.37 \\
0.37 \\
103.30 \\
\end{array}$ & $\begin{array}{c}11,667 \\
0.24 \\
0.24 \\
65.29 \\
\end{array}$ & $\begin{array}{c}22,160 \\
0.38 \\
0.38 \\
186.6 \\
\end{array}$ & $\begin{array}{c}10,680 \\
0.42 \\
0.41 \\
74.91 \\
\end{array}$ & $\begin{array}{c}10,777 \\
0.43 \\
0.43 \\
89.59 \\
\end{array}$ & $\begin{array}{c}18,596 \\
0.36 \\
0.36 \\
128.9 \\
\end{array}$ & $\begin{array}{c}9,979 \\
0.38 \\
0.38 \\
91.09 \\
\end{array}$ & $\begin{array}{c}20,534 \\
0.32 \\
0.32 \\
117.9 \\
\end{array}$ & $\begin{array}{c}5,381 \\
0.16 \\
0.15 \\
23.07 \\
\end{array}$ \\
\hline
\end{tabular}

Table 5: Sharewise stock opinions and six-month buy-and-hold returns (Panel B)

The table reports the results of our panel regressions with stock and time fixed effects using six month buy-and-hold return as dependent variable. Stock opinions are lagged by six months. We use robust standard errors clustered at the individual stock level to mitigate possible issues due to heteroskedasticity and serial correlation. $t$-statistics are in parentheses. Data on crowd stock opinions are from Sharewise. Stock price data and fundamentals are from Thomson Reuters Datastream and Worldscope, Google search volume data are from Google trends, and News sentiment data are from Quandl. In total, our sample runs from August 1, 2007, to July 15, 2015, and contains 73,015 stock-quarter observations. Detailed data definitions and data sources can be found in Table A.1. 


\begin{tabular}{|c|c|c|c|c|c|c|}
\hline & Model (1) & Model (2) & Model (3) & Model (4) & Model (5) & Model (6) \\
\hline & Full sample & Full sample & Low Consensus & High Consensus & High Potential vola & High Sell Potential \\
\hline Potential & $\begin{array}{c}0.091 \\
(14.31)\end{array}$ & $\begin{array}{l}0.069 \\
(8.51)\end{array}$ & $\begin{array}{c}0.108 \\
(3.70)\end{array}$ & $\begin{array}{l}0.083 \\
(5.44)\end{array}$ & $\begin{array}{c}0.048 \\
(5.02)\end{array}$ & $\begin{array}{l}0.106 \\
(4.63)\end{array}$ \\
\hline Analyst opinion & & $\begin{array}{l}0.156 \\
(6.29)\end{array}$ & $\begin{array}{l}0.239 \\
(3.28)\end{array}$ & $\begin{array}{l}0.183 \\
(3.23)\end{array}$ & $\begin{array}{l}0.162 \\
(5.25)\end{array}$ & $\begin{array}{l}0.364 \\
(4.76)\end{array}$ \\
\hline Google search volume & & $\begin{array}{c}0.001 \\
(1.86)\end{array}$ & $\begin{array}{l}0.001 \\
(1.01)\end{array}$ & $\begin{array}{c}0.001 \\
(1.79)\end{array}$ & $\begin{array}{l}0.001 \\
(1.91)\end{array}$ & $\begin{array}{l}0.000 \\
(0.61)\end{array}$ \\
\hline Illiquidity & & $\begin{array}{l}18.49 \\
(9.68)\end{array}$ & $\begin{array}{l}20.79 \\
(1.94)\end{array}$ & $\begin{array}{l}16.21 \\
(6.75)\end{array}$ & $\begin{array}{l}16.15 \\
(5.88)\end{array}$ & $\begin{array}{c}1.57 \\
(0.06)\end{array}$ \\
\hline Constant & $\begin{array}{c}-0.223 \\
(-13.86) \\
\end{array}$ & $\begin{array}{l}-0.228 \\
(-9.76) \\
\end{array}$ & $\begin{array}{l}-0.230 \\
(-1.87) \\
\end{array}$ & $\begin{array}{c}-0.344 \\
(-11.18) \\
\end{array}$ & $\begin{array}{l}-0.305 \\
(-8.87) \\
\end{array}$ & $\begin{array}{l}-0.097 \\
(-0.47) \\
\end{array}$ \\
\hline $\begin{array}{l}\text { Stock fixed effects } \\
\text { Time fixed effects }\end{array}$ & $\begin{array}{l}\text { Yes } \\
\text { Yes }\end{array}$ & $\begin{array}{l}\text { Yes } \\
\text { Yes }\end{array}$ & $\begin{array}{l}\text { Yes } \\
\text { Yes }\end{array}$ & $\begin{array}{l}\text { Yes } \\
\text { Yes }\end{array}$ & $\begin{array}{l}\text { Yes } \\
\text { Yes }\end{array}$ & $\begin{array}{l}\text { Yes } \\
\text { Yes }\end{array}$ \\
\hline $\begin{array}{l}\text { Observations } \\
\mathrm{R}^{2} \\
\text { Adj. } \mathrm{R}^{2} \\
\mathrm{~F}\end{array}$ & $\begin{array}{c}73,015 \\
0.23 \\
0.23 \\
299.80\end{array}$ & $\begin{array}{c}49,617 \\
0.27 \\
0.27 \\
221.60\end{array}$ & $\begin{array}{c}1,679 \\
0.41 \\
0.40 \\
14.38\end{array}$ & $\begin{array}{c}9,990 \\
0.29 \\
0.29 \\
64.73\end{array}$ & $\begin{array}{c}29,199 \\
0.30 \\
0.30 \\
165.20\end{array}$ & $\begin{array}{c}8,543 \\
0.22 \\
0.22 \\
24.12\end{array}$ \\
\hline
\end{tabular}

Table 6: Sharewise stock opinions and abnormal returns (Panel A)

The table reports the results of our panel regressions with stock and time fixed effects on abnormal returns over a six month period. Stock opinions are lagged by six months. We use robust standard errors clustered at the individual stock level to mitigate possible issues due to heteroskedasticity and serial correlation. $t$-statistics are in parentheses. Data on crowd stock opinions are from Sharewise. Stock price data and fundamentals are from Thomson Reuters Datastream and Worldscope, and Google search volume data are from Google trends. In total, our sample runs from August 1, 2007, to July 15, 2015, and contains 73,015 stock-quarter observations. Detailed data definitions and data sources can be found in Table A.1 


\begin{tabular}{|c|c|c|c|c|c|c|c|c|c|}
\hline & $\begin{array}{l}\text { Model (1) } \\
\end{array}$ & $\begin{array}{l}\text { Model (2) } \\
\end{array}$ & $\begin{array}{l}\text { Model (3) } \\
\end{array}$ & $\begin{array}{l}\text { Model (4) } \\
\end{array}$ & $\begin{array}{l}\text { Model (5) } \\
\end{array}$ & $\begin{array}{l}\text { Model (6) } \\
\end{array}$ & $\begin{array}{l}\text { Model (7) } \\
\end{array}$ & $\begin{array}{l}\text { Model (8) } \\
\end{array}$ & $\begin{array}{l}\text { Model (9) } \\
\end{array}$ \\
\hline & Hard to Value & Easy to Value & Loser Stocks & Low Attention & High Attention & Few Opinions & Many Opinions & Earnings surprises & News Sentiment \\
\hline Potential & $\begin{array}{l}0.112 \\
(7.21)\end{array}$ & $\begin{array}{l}0.016 \\
(1.91)\end{array}$ & $\begin{array}{l}0.102 \\
(7.13)\end{array}$ & $\begin{array}{l}0.109 \\
(6.91)\end{array}$ & $\begin{array}{l}0.146 \\
(8.11)\end{array}$ & $\begin{array}{l}0.055 \\
(5.08)\end{array}$ & $\begin{array}{l}0.100 \\
(4.24)\end{array}$ & $\begin{array}{l}0.078 \\
(6.87)\end{array}$ & $\begin{array}{l}0.132 \\
(6.15)\end{array}$ \\
\hline Analyst opinion & $\begin{array}{l}0.224 \\
(5.69)\end{array}$ & $\begin{array}{l}0.164 \\
(3.73)\end{array}$ & $\begin{array}{l}0.158 \\
(3.52)\end{array}$ & $\begin{array}{l}0.328 \\
(6.39)\end{array}$ & $\begin{array}{l}0.269 \\
(5.40)\end{array}$ & $\begin{array}{l}0.295 \\
(8.30)\end{array}$ & $\begin{array}{l}0.115 \\
(2.22)\end{array}$ & $\begin{array}{l}0.157 \\
(4.51)\end{array}$ & $\begin{array}{l}0.294 \\
(3.65)\end{array}$ \\
\hline Google search volume & $\begin{array}{l}0.002 \\
(2.20)\end{array}$ & $\begin{array}{l}0.000 \\
(0.51)\end{array}$ & $\begin{array}{l}0.001 \\
(1.41)\end{array}$ & $\begin{array}{l}-0.000 \\
(-0.12)\end{array}$ & $\begin{array}{l}0.001 \\
(1.01)\end{array}$ & $\begin{array}{l}0.001 \\
(1.44)\end{array}$ & $\begin{array}{l}-0.000 \\
(-0.55)\end{array}$ & $\begin{array}{l}0.001 \\
(1.17)\end{array}$ & $\begin{array}{l}0.002 \\
(2.05)\end{array}$ \\
\hline Illiquidity & $\begin{array}{l}20.95 \\
(6.27)\end{array}$ & $\begin{array}{l}13.45 \\
(1.28)\end{array}$ & $\begin{array}{l}14.95 \\
(3.55)\end{array}$ & $\begin{array}{l}19.91 \\
(5.18)\end{array}$ & $\begin{array}{l}20.34 \\
(3.05)\end{array}$ & $\begin{array}{l}17.69 \\
(4.63)\end{array}$ & $\begin{array}{l}23.60 \\
(3.57)\end{array}$ & $\begin{array}{l}25.65 \\
(4.03)\end{array}$ & $\begin{array}{l}184.80 \\
(2.00)\end{array}$ \\
\hline Earnings surprises & & & & & & & & $\begin{array}{l}0.000 \\
(2.96)\end{array}$ & \\
\hline News sentiment & & & & & & & & & $\begin{array}{l}-0.054 \\
(-2.66)\end{array}$ \\
\hline Constant & $\begin{array}{l}-0.293 \\
(-5.14)\end{array}$ & $\begin{array}{l}-0.213 \\
(-3.45)\end{array}$ & $\begin{array}{l}-0.212 \\
(-7.06)\end{array}$ & $\begin{array}{l}-0.232 \\
(-3.90)\end{array}$ & $\begin{array}{l}-0.237 \\
(-3.76)\end{array}$ & $\begin{array}{l}-0.346 \\
(-3.06)\end{array}$ & $\begin{array}{l}-0.198 \\
(-5.40)\end{array}$ & $\begin{array}{l}-0.185 \\
(-5.57)\end{array}$ & $\begin{array}{l}0.009 \\
(0.20)\end{array}$ \\
\hline $\begin{array}{l}\text { Stock fixed effects } \\
\text { Time fixed effects }\end{array}$ & $\begin{array}{l}\text { Yes } \\
\text { Yes }\end{array}$ & $\begin{array}{l}\text { Yes } \\
\text { Yes }\end{array}$ & $\begin{array}{l}\text { Yes } \\
\text { Yes }\end{array}$ & $\begin{array}{l}\text { Yes } \\
\text { Yes }\end{array}$ & $\begin{array}{l}\text { Yes } \\
\text { Yes }\end{array}$ & $\begin{array}{l}\text { Yes } \\
\text { Yes }\end{array}$ & $\begin{array}{l}\text { Yes } \\
\text { Yes }\end{array}$ & $\begin{array}{l}\text { Yes } \\
\text { Yes }\end{array}$ & $\begin{array}{l}\text { Yes } \\
\text { Yes }\end{array}$ \\
\hline $\begin{array}{l}\text { Observations } \\
\mathrm{R}^{2} \\
\text { Adj. } \mathrm{R}^{2} \\
\mathrm{~F} \\
\end{array}$ & $\begin{array}{c}13,155 \\
0.30 \\
0.30 \\
91.19 \\
\end{array}$ & $\begin{array}{c}12,985 \\
0.18 \\
0.18 \\
61.61 \\
\end{array}$ & $\begin{array}{c}12,171 \\
0.36 \\
0.36 \\
110.60 \\
\end{array}$ & $\begin{array}{c}11,857 \\
0.34 \\
0.34 \\
59.09 \\
\end{array}$ & $\begin{array}{c}12,207 \\
0.35 \\
0.35 \\
76.91 \\
\end{array}$ & $\begin{array}{c}21,087 \\
0.29 \\
0.29 \\
122.00 \\
\end{array}$ & $\begin{array}{c}10,499 \\
0.32 \\
0.32 \\
69.22 \\
\end{array}$ & $\begin{array}{c}23,148 \\
0.25 \\
0.25 \\
95.91 \\
\end{array}$ & $\begin{array}{c}6,511 \\
0.09 \\
0.09 \\
24.53 \\
\end{array}$ \\
\hline
\end{tabular}

Table 6: Sharewise stock opinions and abnormal returns (Panel B)

The table reports the results of our panel regressions with stock and time fixed effects on abnormal returns over a six month period. Stock opinions are lagged by six months. We use robust standard errors clustered at the individual stock level to mitigate possible issues due to heteroskedasticity and serial correlation. $t$-statistics are in parentheses. Data on crowd stock opinions are from Sharewise. Stock price data and fundamentals are from Thomson Reuters Datastream and Worldscope, Google search volume data are from Google trends, and News sentiment data are from Quandl. In total, our sample runs from August 1, 2007, to July 15, 2015, and contains 73,015 stock-quarter observations. Detailed data definitions and data sources can be found in Table A.1 


\begin{tabular}{|c|c|c|}
\hline Variable name & Definition & Data source \\
\hline Potential & Sharewise crowd stock assessment consensus (expected stock return). & Sharewise. \\
\hline Total opinion & Number of total opinions transmitted through Sharewise. & Sharewise. \\
\hline Total buy & Number of total buy recommendations by the Sharewise community. & Sharewise. \\
\hline Total sell & Number of total sell recommendations by the Sharewise community. & Sharewise. \\
\hline $6 \mathrm{M}$ buy-hold & Six month buy and hold return. & Datastream, own calc. \\
\hline Abnormal return & Six month abnormal return. & Datastream, own calc. \\
\hline \multirow[t]{2}{*}{ Illiquidity } & $\begin{array}{l}\text { Amihud measure of an individual stock's illiquidity adjusted following the } \\
\text { procedure proposed by Karolyi et al. (2012). The adjusted Amihud measure }\end{array}$ & Datastream, own calc. \\
\hline & $\begin{array}{l}\text { is defined as }-\ln \left(1+\frac{\left|R_{i, t}\right|}{P_{i, t} V O_{i, t}}\right) \text {, where } R_{i, t} \text { is the return, } P_{i, t} \text { is the price } \\
\text { and } V O_{i, t} \text { is the trading volume of stock } i \text { on day } t .\end{array}$ & \\
\hline Stock volatility & $\begin{array}{l}\text { Conditional volatility of stock returns estimated with GARCH }(1,1) \text { model } \\
\text { based on daily closing prices. }\end{array}$ & Datastream, own calc. \\
\hline Potential volatility & $\begin{array}{l}\text { Conditional volatility of expected stock returns (crowd opinions) estimated } \\
\text { with } \operatorname{GARCH}(1,1) \text { model based on daily opinions. }\end{array}$ & Sharewise, own calc. \\
\hline Stock market return & Log stock market returns of the appropriate benchmark index. & Datastream, own calc. \\
\hline Risk free rate & Level of the risk free interest rate. & Datastream. \\
\hline
\end{tabular}

Table A.1: Variable definitions and data sources.

The table presents both definitions and data sources for all dependent and independent variables that are used in our empirical study. 


\begin{tabular}{|c|c|c|}
\hline Variable name & Definition & Data source \\
\hline Total assets & Natural logarithm of a firm's total assets (given in Mio. USD). & $\begin{array}{l}\text { Worldscope } \\
\text { (WC02999). }\end{array}$ \\
\hline Book value & Book value of common equity. & $\begin{array}{l}\text { Worldscope } \\
\text { (WC07210). }\end{array}$ \\
\hline Market value & Market value of common equity. & $\begin{array}{l}\text { Worldscope } \\
\text { (WC03501). }\end{array}$ \\
\hline Book-to-market & Book value of common equity divided by market value of common equity. & $\begin{array}{l}\text { Worldscope (WC07210 } \\
\text { and WC03501). }\end{array}$ \\
\hline Dividend yield & Dividend per share as a percentage of the share price & $\begin{array}{l}\text { Worldscope } \\
\text { (WC02999). }\end{array}$ \\
\hline Earnings surprises & Quarterly earnings surprise & $\begin{array}{l}\text { Thomson Reuters (EP- } \\
\text { SActSurprise). }\end{array}$ \\
\hline Analyst opinion & Professional analyst stock assessment consensus (expected stock return). & Datastream. \\
\hline Google search volume & Stocks' relative Google search requests over time. & Google trends. \\
\hline News sentiment & $\begin{array}{l}\text { Average sentiment of all articles related to the entity. Values between }-1 \text { and } \\
1 .\end{array}$ & $\begin{array}{l}\text { Quandl Alpha One } \\
\text { Sentiment }\end{array}$ \\
\hline 52-week-high & Distance of current stock price to 52 -week-high. & Datastream, own calc. \\
\hline 52-week-low & Distance of current stock price to 52 -week-low. & Datastream, own calc. \\
\hline
\end{tabular}

Table A.1: Variable definitions and data sources (cont.). 